\title{
Changes in DNA methylation hallmark alterations in chromatin accessibility and gene expression for eye lens differentiation
}

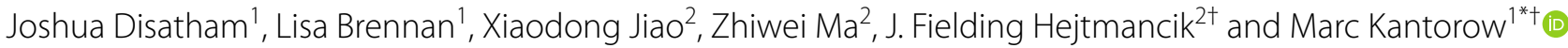

\begin{abstract}
Background: Methylation at cytosines (mCG) is a well-known regulator of gene expression, but its requirements for cellular differentiation have yet to be fully elucidated. A well-studied cellular differentiation model system is the eye lens, consisting of a single anterior layer of epithelial cells that migrate laterally and differentiate into a core of fiber cells. Here, we explore the genome-wide relationships between mCG methylation, chromatin accessibility and gene expression during differentiation of eye lens epithelial cells into fiber cells.
\end{abstract}

Results: Whole genome bisulfite sequencing identified 7621 genomic loci exhibiting significant differences in mCG levels between lens epithelial and fiber cells. Changes in MCG levels were inversely correlated with the differentiation state-specific expression of 1285 genes preferentially expressed in either lens fiber or lens epithelial cells (Pearson correlation $r=-0.37, p<1 \times 10^{-42}$ ). mCG levels were inversely correlated with chromatin accessibility determined by assay for transposase-accessible sequencing (ATAC-seq) (Pearson correlation $r=-0.86, p<1 \times 10^{-300}$ ). Many of the genes exhibiting altered regions of DNA methylation, chromatin accessibility and gene expression levels in fiber cells relative to epithelial cells are associated with lens fiber cell structure, homeostasis and transparency. These include lens crystallins (CRYBA4, CRYBB1, CRYGN, CRYBB2), lens beaded filament proteins (BFSP1, BFSP2), transcription factors (HSF4, SOX2, HIF1A), and Notch signaling pathway members (NOTCH1, NOTCH2, HEY1, HES5). Analysis of regions exhibiting cell-type specific alterations in DNA methylation revealed an overrepresentation of consensus sequences of multiple transcription factors known to play key roles in lens cell differentiation including HIF1A, SOX2, and the MAF family of transcription factors.

Conclusions: Collectively, these results link DNA methylation with control of chromatin accessibility and gene expression changes required for eye lens differentiation. The results also point to a role for DNA methylation in the regulation of transcription factors previously identified to be important for lens cell differentiation.

Keywords: DNA methylation, Bisulfite sequencing, RNA-seq, ATAC-seq, Lens, Differentiation, Gene regulation, Chromatin, Transcriptional regulation

*Correspondence: mkantoro@health.fau.edu

${ }^{\dagger} \mathrm{J}$. Fielding Hejtmancik and Marc Kantorow contributed equally to this work

${ }^{1}$ Department of Biomedical Science, Charles E. Schmidt College of Medicine, Florida Atlantic University, Boca Raton, FL, USA

Full list of author information is available at the end of the article

\section{Background}

It is well-accepted that epigenetic mechanisms can regulate cellular differentiation pathways required for the form and function of mature tissues [1-3]. Many of these pathways culminate in chromatin accessibility changes that modulate the ability of required transcription factors (TFs) to activate or repress the expression of specific 
genes through altered access and binding to key cis-regulatory sequences [4-6].

A major epigenetic mechanism regulating gene expression is DNA methylation at cytosine residues to produce methyl cytosine $(\mathrm{mC})$. DNA methylation at cytosine residues occurs at CG, CHG, and $\mathrm{CHH}$ nucleotides (where $\mathrm{H}$ represents $\mathrm{A}, \mathrm{T}$, or $\mathrm{C}$ ). Production of $\mathrm{mC}$ is dependent on the activities of DNA methyltransferases (DNMTs) that require $\mathrm{S}$-adenosylmethionine that acts as a methyl donor [7-10]. Increased levels of DNA methylation are associated with nucleosome compaction and reduced accessibility of TFs to their cognate binding regions resulting in altered gene expression [8, 11-13]. In addition, the presence of $\mathrm{mCG}$ in TF binding sites can alter their DNA binding affinities $[8,14-18]$ to modulate gene expression. Consistent with these properties, DNA methylation has been shown to be important for the development, differentiation or maturation of embryonic stem cells [19], auditory epithelium [14], muscle [20, 21], adipocytes [22], trophoblasts [23], and chondrocytes [24].

Here, we examined the potential role of DNA methylation on the modulation of chromatin accessibility changes and the expression of key genes required for the differentiation of immature eye lens cells into mature transparent cells. A major feature of the lens is that, unlike many tissues, it grows both embryologically and throughout adult life through execution of a continuous cellular differentiation program resulting in two morphologically distinct cell populations [25]. The lens comprises an anterior surface monolayer of undifferentiated epithelial cells that, upon withdrawing from the cell cycle, differentiate into elongated, organelle-free lens fiber cells that make up the bulk of the lens, including undergoing karyolysis in the lens central nucleus [25-40]. These differentiation statespecific and morphologically distinct cellular populations can be isolated in quantities sufficient for molecular and biochemical analysis through microdissection [32, 35].

Lens cell differentiation is hallmarked by the expression of critical regulatory and structural genes [35, 41-43]. The differentiation state-specific expression patterns of these genes suggests that specific regulatory mechanisms operate to govern their expression levels during lens cell differentiation. Consistently, previous studies have identified multiple transcription factors [25, 28, 29, 41, 44-46] required for their differentiation state-specific expression patterns. Recently, epigenetic programming was shown to play an important role in the regulation of gene expression during lens fiber cell differentiation since ATAC (assay for transposase-accessible chromatin) sequencing of undifferentiated lens epithelial and differentiated fiber cells identified genome-wide changes in chromatin accessibility associated with the expression of multiple genes during lens differentiation [32, 47].
Here, we explored the role of epigenetic programming in control of lens cell differentiation by interrogating the differentiation state-specific relationship between DNA methylation, chromatin accessibility and gene expression levels between chicken lens epithelial and fiber cells using a combination of bisulfite sequencing, ATACseq and RNA-seq. Our analysis revealed that specific genomic DNA methylation patterns characterize the differentiation states of lens cells and that specific DNA methylation signatures correlate with differentiation state-specific changes in chromatin accessibility and gene expression levels. Examination of individual gene functions implicates DNA methylation as a factor in the regulation of multiple important lens functions including lens cell structure, homeostasis, and transparency. Analysis of DNA sequences with altered DNA methylation levels revealed the presence of consensus binding sequences for a wide variety of transcription factors known to regulate lens differentiation state-specific gene expression.

Collectively, these results establish DNA methylation as a key feature of lens cell differentiation and implicate specific DNA methylation signatures in the regulation of chromatin accessibility and gene expression. They also provide evidence that key DNA methylation patterns govern the binding, activity and availability of established transcription factors known to be required for lens differentiation. Finally, they provide a blueprint for studies aimed at identifying the role of DNA methylation in the differentiation of more complex tissues.

\section{Results}

Lens epithelial and fiber cells show differentiation state-specific patterns of genome-wide DNA methylation

A combination of RNA-sequencing (RNAseq), whole genome bisulfite sequencing (WGBS) and chromatin accessibility (ATAC-seq) was employed to elucidate the potential role of DNA methylation in the regulation of chromatin structure and gene expression and thus lens cell differentiation (Fig. 1). 25 lenses per biological replicate from embryonic day 13 (E13) chick were microdissected into lens epithelial cell populations that comprised both the central and equatorial lens epithelia and lens fiber cell populations comprising both the peripheral and central lens fibers. The microdissected lens cell populations were subjected to genome-wide bisulfite sequencing. A total of 6 samples from two groups (three biological replicates of lens epithelial cells and three biological replicates of lens fiber cells) were examined yielding at least 125 million clean reads per sample with an average mapping rate of $83.54 \%$. Pearson correlation analysis of the samples followed by dendrogram clustering confirmed that biological replicates from the same groups are more strongly correlated than replicates from 
different groups (Additional file 1: Figure S1A, B, lens epithelial cells Pearson's $r=0.965-0.972$, lens fiber cells Pearson's $r=0.967-0.976$, lens fiber cells to epithelial cells Pearson's $r=0.941-0.963)$. These results confirm the reliability and reproducibility of the bisulfite sequencing data.

Genome-wide DNA methylation patterns detected in lens epithelial cells and fiber cells were mapped and quantified. Of the 446 million cytosines in the embryonic chick lens genome, between 3.4 and $4 \%$ were methylated in lens epithelial or fiber cells, with a large majority of methylated cytosines ( $>91 \%$ ) being present in mCG dinucleotide pairs (Fig. 2A, Additional file 5: Table S1). This result is consistent with previous studies in other vertebrate animal model systems and tissues that also exhibit a greater proportion of $\mathrm{mCG}[14,48]$. Subsequent examination of the global methylation levels (ratio of $\mathrm{mCG} / \mathrm{CG}$ ) across different genomic regions revealed that fiber cells exhibited a higher overall degree of methylation than epithelial cells at presumptive promoter regions (2 $\mathrm{kb}$ upstream of gene transcription start sites), gene bodies (utr5, exon, intron, utr3), CpG islands in intergenic regions (CGI) and their immediate 2-kb flanking regions (CGI shore), and repeat regions (low complexity DNA regions) (Fig. 2B, Additional file 1: Figure S1C).

Differentially methylated regions (DMRs) are established regulators of major gene expression changes [8, $49,50]$. Our analysis identified 7621 total mCG DMRs across the E13 embryonic chick lens genome. These 7621 regions contained differentiation state-specific differences in mCG methylation levels in lens epithelial cells compared to lens fiber cells. A majority of these regions $(78.59 \%)$ were mapped to gene bodies (utr5, utr3, 1st exon, 1st intron, other exon, other intron) while $12.14 \%$ mapped to presumptive promoter regions (within $2 \mathrm{~kb}$ upstream from transcription start site). A minority were mapped to intergenic regions (8.04\%) (Fig. 2C). To determine whether the observed distribution of mCG DMRs could have occurred by chance, we compared the distribution patterns of differentially methylated regions between lens epithelial and fiber cells to a computer-generated random distribution of differentially methylated regions across the genome. We found that $7621 \mathrm{mCG}$ DMRs clustered more in genebody and promoter regions and less in proximal downstream and distal intergenic regions than what would be expected if the distribution were due to random chance (Fig. 2D, Chi-square $p<1 \times 10^{-300}$ ). Of the 7621 identified mCG differentially methylated regions, a large majority (6601) were hypermethylated in fiber cells compared to epithelial cells, while a smaller group (1020) were hypomethylated in fiber cells compared to epithelial cells (Fig. 2E, Additional file 6: Table S2). Classifying the mCG DMRs based on genomic region also revealed that most genomic regions containing mCG DMRs have increased methylation in fiber cells compared to epithelial cells. Interestingly, there are significant differences in the genomic distribution of hypermethylated regions versus the distribution of hypomethylated regions (Additional file 1: Figure S1D, Chi-square $\left.p<1 \times 10^{-81}\right)$. Specifically, regions that were hypermethylated in fiber cells relative to epithelial cells tend to cluster more in exons and proximal promoter regions $(\leq 1 \mathrm{~kb}$ upstream from gene transcription start sites) and regions that were hypomethylated in fiber cells relative to epithelial cells tend to cluster more in introns, intergenic, and distal promoter regions (1-2 kb upstream from gene transcription start sites). This asymmetric distribution of hypomethylated regions versus hypermethylated regions has also been reported in a previous study comparing DNA methylation patterns across tumor types [51]. A possible explanation for this asymmetric distribution is that certain regulatory elements in the proximal promoter $(\leq 1 \mathrm{~kb}$ from TSS), and exons are required for epithelial cell gene expression that upon hypermethylation, lead to decreased expression in the fiber cells. In contrast certain regulatory elements found in the distal promoters (1-2 kb from TSS), regions might be required for fiber cell introns, and distal intergenic gene expression and are only active once these sites become hypomethylated.

Collectively, these data identify significant differences in DNA methylation patterns between lens epithelial and fiber cells and they suggest that changes in DNA methylation are a major feature of the lens differentiation program.

\footnotetext{
(See figure on next page.)

Fig. 1 Multiomics analysis combines high-throughput sequencing techniques to elucidate novel features of lens differentiation. Workflow of the multiomics-based approach. Biological triplicate pools of 25 lenses from E13 embryonic chick were microdissected into undifferentiated lens epithelial cells and differentiated lens fiber cells. RNA isolated from samples was used for RNAseq to elucidate differentially expressed genes. Genomic DNA (gDNA) isolated from samples was used for whole genome bisulfite sequencing (WGBS) to elucidate differentially methylated genomic regions. ATACseq data from a previously published study on microdissected lenses from E13 embryonic chick [217] were used to identify changes in chromatin accessibility. Integrating these data reveal the range and spectrum of lens gene expression patterns characterized by specific methylation patterns and chromatin accessibility during lens cell differentiation. Transcription factor binding site (TFBS) and transcription factor (TF) motif analysis and gene ontology (GO) analysis was also performed
} 


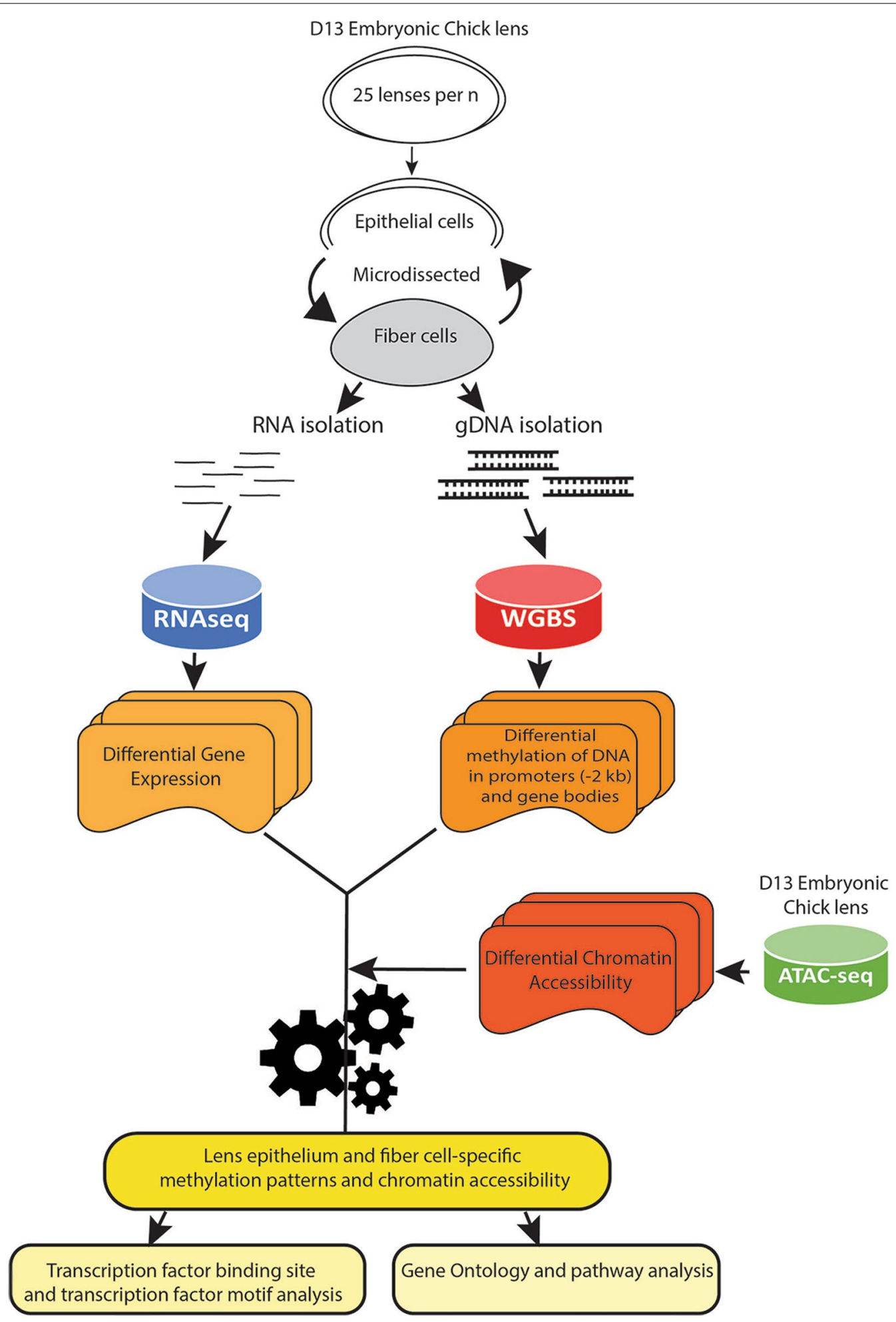

Fig. 1 (See legend on previous page.) 

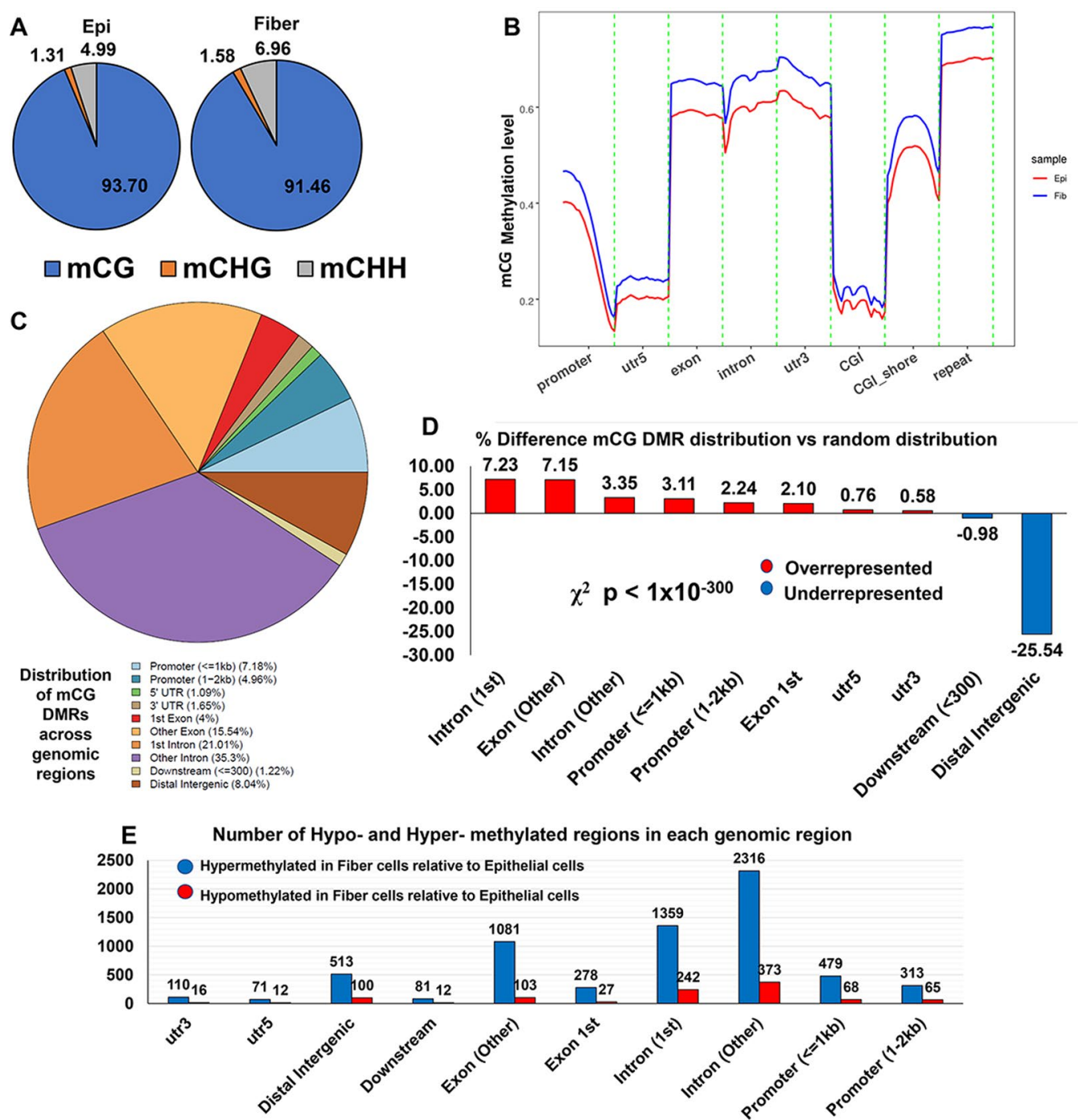

Fig. 2 Differentiation-state-specific patterns of genome-wide DNA methylation are detected between lens epithelial and fiber cells. A Proportion of methylcytosines (mCs) that are $\mathrm{mCG}, \mathrm{mCHG}$, or $\mathrm{mCHH}$ found in lens epithelial and fiber cells. $\mathbf{B}$ mCG methylation levels at indicated genomic regions in lens epithelial and fiber cells. C Distribution of mCG differentially methylated regions (DMRs) at indicated genomic regions. D Percentage distribution of $\mathrm{mCG}$ DMRs at indicated genomic regions relative to random distribution across the genome. Positive values indicate that $\mathrm{mCG}$ DMRs cluster in the indicated genomic region are in excess of what is expected due to a random distribution while negative values indicate that mCG DMRs cluster in the indicated genomic region are less than what is expected due to a random distribution. E Number of hypo- and hyper-methylated regions at indicated genomic regions. Hypomethylated regions are demethylated in lens fiber cells compared to lens epithelial cells while hypermethylated regions are more methylated in lens fiber cells compared to lens epithelial cells

\section{RNA-sequencing reveals novel lens epithelial cell and fiber} cell gene expression patterns

As a first step towards establishing the role of DNA methylation in lens cell differentiation, levels of DNA methylation were correlated with specific gene expression changes occurring during lens cell differentiation as established by RNA-seq of microdissected lens epithelia and fiber cells.

Twenty-five lenses per biological replicate from embryonic day 13 (E13) chick were microdissected into specific epithelial and fiber cell populations and RNAseq was conducted. One thousand six hundred and twenty-seven genes exhibited significantly higher levels of expression in fiber cells relative to epithelial cells $(\log 2 \mathrm{FC}>0.4, q<0.05)$ and 2955 genes had significantly lower levels of expression in fiber cells compared to epithelial cells $(\log 2 \mathrm{FC}<-0.4, q<0.05)$ (Fig. 3A, Additional file 7: Table S3). Consistent with their previously established expression patterns [35], the top 60 differentially expressed genes between lens epithelial and fiber cells 


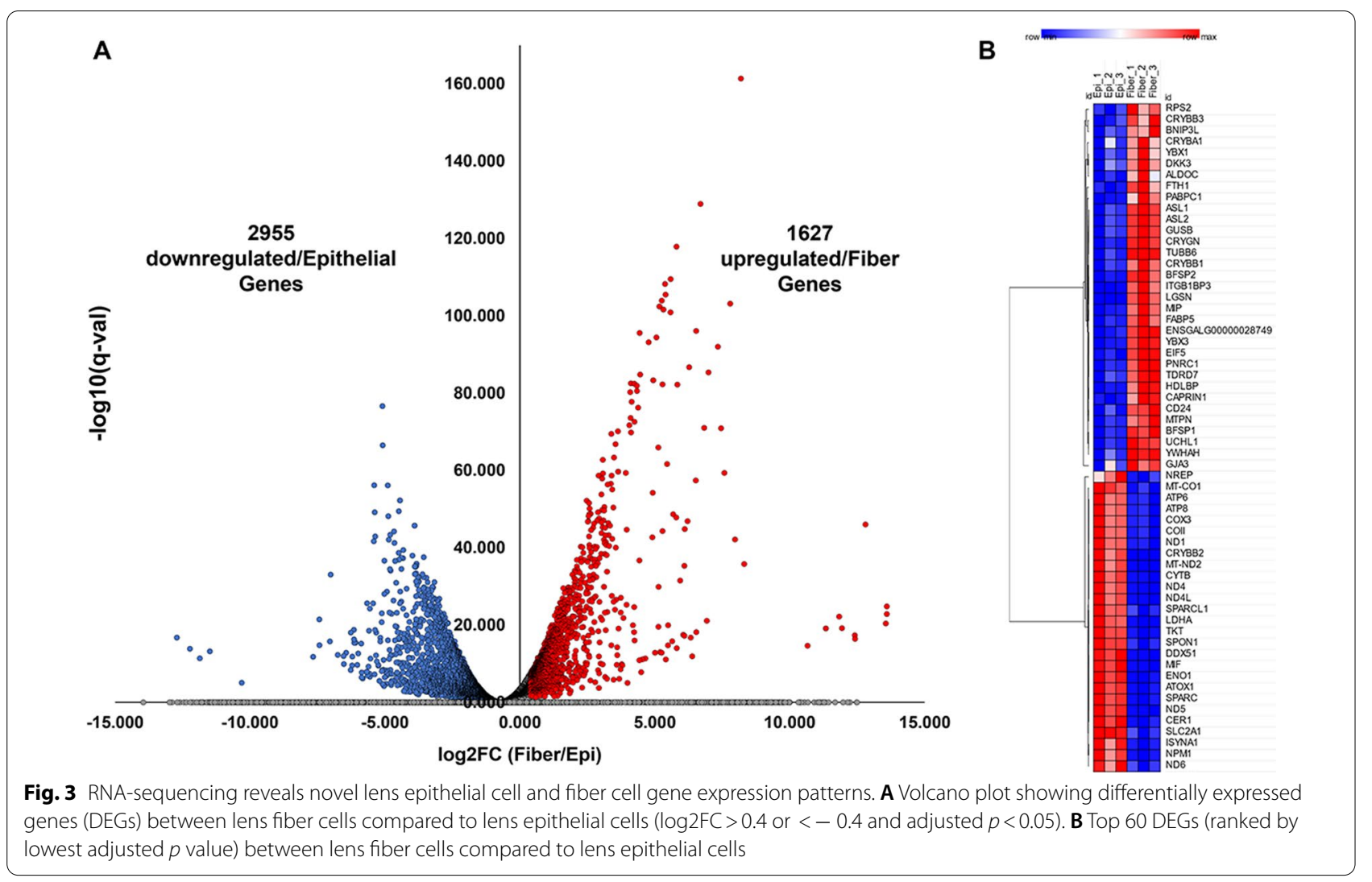

(ranked by lowest adjusted $p$ value) included crystallins (CRYBB3, CRYBA1, ASL1, ASL2, CRYGN, CRYBB1), beaded filament proteins (BFSP1, BFSP2), and the RNA binding protein (TDRD7) and connexin (GJA3) (Fig. 3B). An analysis of biological pathways specific to identified gene expression differences between these cell populations using Enrichr [52-54] identified a wide variety of significantly enriched biological processes and pathways associated with the top 200 epithelial cell genes $(\log 2 \mathrm{FC}<-0.4, q<0.05$, ranked by highest FPKM in epithelial cells to lowest) and the top 200 fiber cell genes $(\log 2 \mathrm{FC}>0.4, q<0.05$, ranked by highest FPKM in fiber cells to lowest) (Additional file 2: Figure S2A-D, Additional file 8: Table S4). The data identify that a majority of differentially expressed genes exhibit decreased expression in lens fiber cells (Fig. 3A) consistent with the overall increase in mCG DNA methylation levels in fiber cells during lens cell differentiation (Fig. 2B).

\section{Differentiation state-specific methylation patterns parallel differentiation state-specific gene expression changes during lens fiber cell differentiation}

To determine the relationship between mCG DNA methylation changes and gene expression changes occurring during the epithelial cell to fiber cell transition, we integrated the bisulfite sequencing methylation data with the RNA-seq data and quantified the average change in mCG methylation for all differentially methylated regions that mapped to the gene bodies and putative promoters $(-2 \mathrm{~kb}$ upstream from transcription start sites) of differentially expressed genes $(\log 2 \mathrm{FC}>0.4$ or $<-0.4$, and $q<0.05)$ (Additional file 9: Table S5A-D). Of all differentially expressed genes detected between epithelial cells and fiber cells (log2-fold change FPKM $>0.4$ or $<-0.4$ and $q<0.05$ ), 1063 exhibited increased average mCG methylation levels in fiber cells, while 222 genes exhibited decreased average mCG methylation levels in fiber cells in gene bodies and putative promoter regions (up to $-2 \mathrm{~kb}$ upstream from the transcription start site). A plot of the $\log 2$-fold change in gene expression levels vs the average difference in mCG methylation levels reveals a significant negative correlation between methylation changes and gene expression changes of those genes identified to exhibit different expression levels between lens epithelial and fiber cells (Fig. 4A, Pearson correlation $r=-0.37, p<1 \times 10^{-42}$ ). These data suggest that increased mCG methylation of gene bodies and putative promoter regions plays a significant role in the regulation of genes during fiber cell differentiation. 

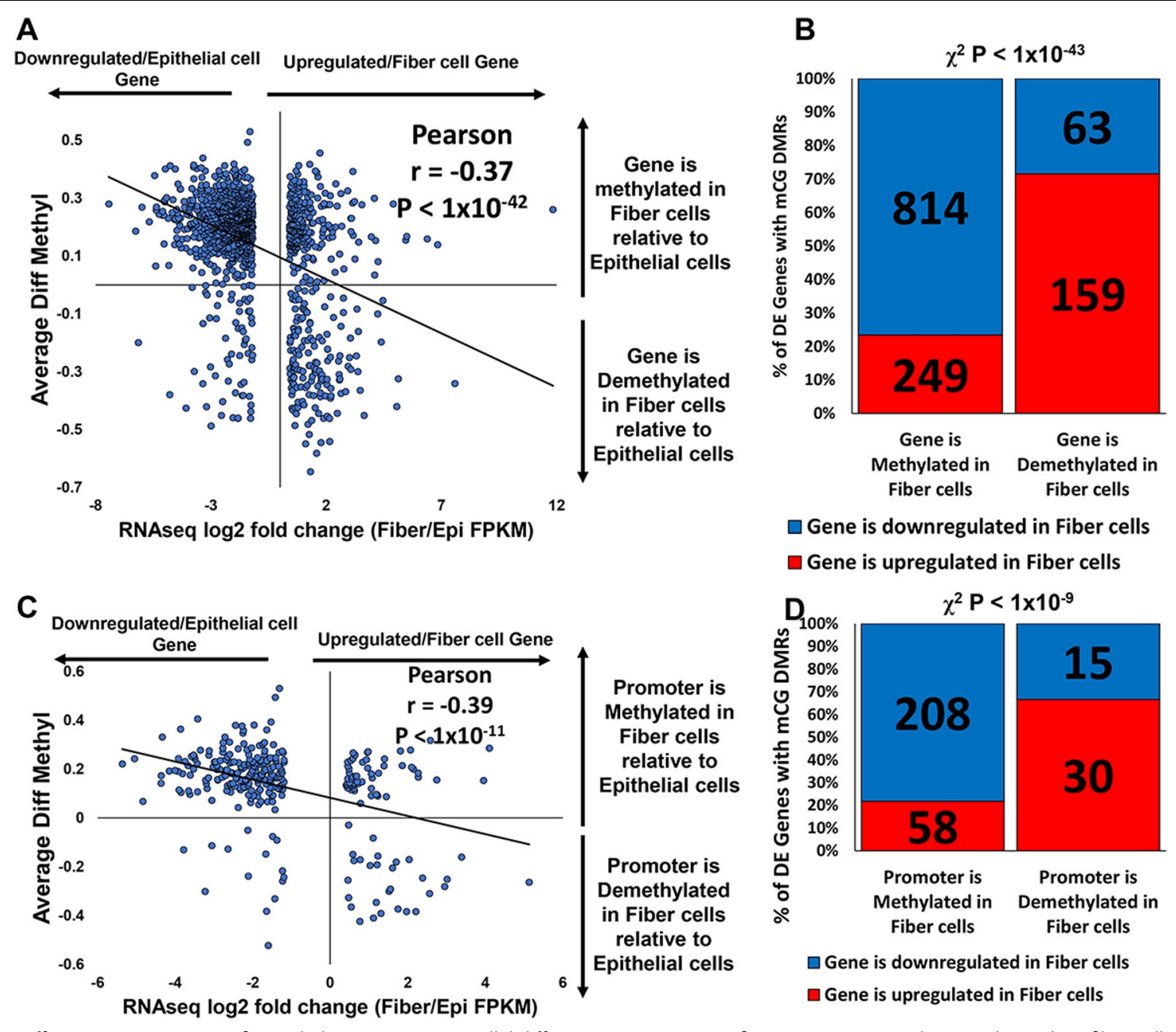

$\square$ Gene is downregulated in Fiber cells

$\square$ Gene is upregulated in Fiber cells

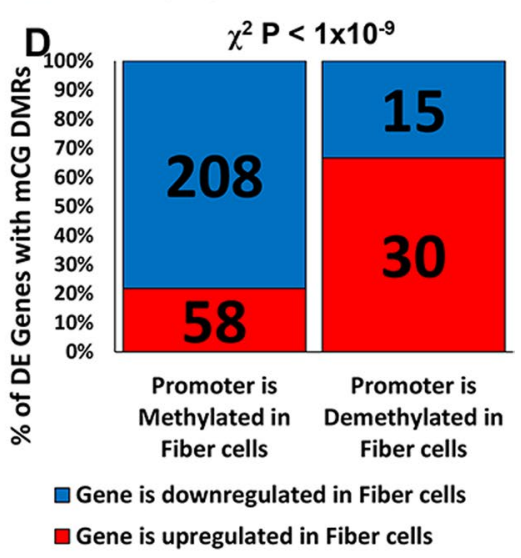

Fig. 4 Differentiation-state-specific methylation patterns parallel differentiation state-specific gene expression changes during lens fiber cell differentiation. A Scatter plot of average change in mCG methylation (Average diff. Methyl) of all mCG DMRs mapped to the promoter ( $-2 \mathrm{~kb}$ upstream of transcription start site) and genebody versus the log2-fold change in gene expression of differentially expressed genes (DEGs) between lens fiber cells and lens epithelial cells. Data indicate only DEGs that contain at least one mCG DMR. Pearson correlation $r=-0.37, p<1 \times 10^{-42}$. B Proportion of DEGs (upregulated/fiber cell gene or downregulated/epithelial cell gene) that also have an increase in average methylation (more methylated in fiber cells compared to epithelial cells) or decrease in average methylation (demethylated in fiber cells compared to epithelial cells) across the promoter and genebody combined. Data indicate only DEGs that contain at least one mCG DMR. $x^{2}$ test, $p<1 \times 10^{-43}$. C Same as $\mathbf{A}$ but only the average change in methylation of mCG DMRs mapped to putative promoters only. Data indicate only DEGs with putative promoters that contain at least one mCG DMR. Pearson correlation $r=-0.39, p<1 \times 10^{-11}$. D Same as $\mathbf{B}$ but only the average change in methylation of $\mathrm{mCG}$ DMRs mapped to putative promoters only. Data indicate only DEGs with putative promoters that contain at least one mCG DMR. $x^{2}$ test, $p<1 \times 10^{-9}$

814 of 1063 genes with increased mCG methylation levels $(76.58 \%)$ in fiber cells also exhibited decreased expression levels in fiber cells relative to epithelial cells (Fig. 4B, Additional file 9: Table S5A). Consistently, 159 of 222 genes exhibiting decreased mCG methylation levels in fiber cells (71.62\%) also exhibited increased expression levels in fiber cells compared to epithelial cells (Fig. 4B, Additional file 9: Table S5B), indicating a very significant association between the identified mCG methylation and gene expression changes (Chisquared test, $\left.p<1 \times 10^{-43}\right)$.
Enrichr analysis of the 814 epithelial cell genes with increased mCG methylation levels in fiber cells (Additional file 9: Table S5A) revealed significant associations with epithelial-to-mesenchymal transition, Notch signaling, UV response, cell cycle control, hypoxia, and regulation of transcription (Additional file 3: Figure S3A, B, Additional file 10: Table S6A, B). Of the 159 fiber cell genes with decreased mCG methylation in fibers (Additional file 9: Table S5B), Enrichr analysis revealed significant functions in hedgehog signaling, cell-cell junction organization, intermediate filament organization, 
cytoplasmic translation and mRNA catabolism (Additional file 3: Figure S3C, D, Additional file 10: Table S6C, D). Collectively, these data suggest that changes in DNA methylation play a significant role in the regulated expression of genes preferentially expressed in either epithelial or fiber cell populations and could indirectly regulate multiple cellular features and functions.

We also conducted a similar analysis restricted to genes with differentially $\mathrm{mCG}$ methylated regions within putative promoter regions (up to $-2 \mathrm{~kb}$ upstream from gene transcription start sites) (Additional file 9: Table S5E-H). Of all differentially expressed genes detected between epithelial cells and fiber cells ( $\log 2$-fold change FPKM $>0.4$ or $<-0.4$ and $q<0.05), 266$ exhibited increased average mCG methylation levels in putative promoter regions ( $-2 \mathrm{~kb}$ upstream from transcription start site) in fiber cells, while 45 genes exhibited decreased average mCG methylation levels in putative promoter regions $(-2 \mathrm{~kb}$ upstream from transcription start site) in fiber cells. A plot of the log2-fold change in gene expression levels vs the average difference in putative promoter $\mathrm{mCG}$ methylation levels revealed a significant negative correlation between putative promoter methylation changes and gene expression changes of those genes identified to exhibit different expression levels between lens epithelial and fiber cells (Fig. 4C, Pearson correlation $r=-0.39$, $p<1 \times 10^{-11}$ ). These data suggest that increased mCG methylation of putative promoter regions plays a significant role in the negative regulation of genes during fiber cell differentiation. 208 of 266 genes (78.20\%) with increased putative promoter mCG methylation levels in fiber cells also exhibited decreased expression levels in fiber cells relative to epithelial cells (Fig. 4D, Additional file 9: Table S5E). By contrast, 30 of 45 genes (66.67\%) with decreased putative promoter mCG methylation levels in fiber cells (65.12\%) also exhibited increased expression levels in fiber cells relative to epithelial cells (Fig. 4D, Additional file 9: Table S5F). A Chi-squared test also confirmed a significant association between the identified methylation and gene expression changes $\left(p<1 \times 10^{-9}\right)$.

Enrichr analysis of the 208 epithelial cell genes with increased putative promoter mCG methylation levels in fiber cells (Additional file 9: Table S5E) revealed significant associations with epithelial-to-mesenchymal transition, Notch signaling, cell cycle control, hypoxia, mTORC1 signaling, hedgehog signaling, and glycolysis (Additional file 3: Figure S3E, F, Additional file 10: Table S6E, F). Of the 30 fiber cell genes with decreased putative promoter mCG methylation in fibers (Additional file 9: Table S5F), Enrichr analysis revealed significant functions in IFN-gamma response, actin filament organization, cell-matrix adhesion, eye development, and negative regulation of epithelial cell proliferation (Additional file 3: Figure S3G, H, Additional file 10: Table S6G, H). Collectively, these data suggest that DNA methylation changes within promoter regions play a significant role in the regulation of differentiation state-specific gene expression during lens cell differentiation and hence in the modulation of cell-type specific functions ranging from structure to homeostasis.

In summary, this analysis provides evidence that DNA methylation of promoter regions, and gene bodies plays a significant role in regulating the differentiation state-specific expression of multiple genes important for a wide variety of lens epithelial cell or fiber cell functions.

\section{Differentiation state-specific methylation patterns parallel changes on chromatin accessibility occurring upon lens fiber cell differentiation}

To identify a possible relationship between DNA methylation and chromatin accessibility, we integrated bisulfite sequencing data and ATAC-seq data [32]. The analysis revealed that 699 regions of DNA exhibiting decreased levels of mCG DNA methylation in fiber cells and 2756 regions of DNA exhibiting increased levels of mCG DNA methylation in fiber cells were contained in chromatin-accessible regions in the lens genome of embryonic day 13 chick lenses. Analysis of this data revealed that $92 \%$ (646 of 699 ) of the regions exhibiting decreased levels of mCG DNA methylation in fiber cells were significantly associated with increased chromatin accessibility in fiber cells relative to epithelia $(\log 2 \mathrm{fc}>0.25$ and $q<0.05)$ (Fig. 5A, Chi-square $p<1 \times 10^{-300}$, Additional file 11: Table S7). Conversely, $72 \%$ (1979 of 2756) of the regions exhibiting increased levels of mCG DNA methylation in fiber cells was significantly associated with decreased chromatin accessibility in fiber cells relative to epithelia $(\log 2 \mathrm{fc}<-0.25$ and $q<0.05)$. Consistently, a significant negative correlation was detected between changes in mCG methylation and chromatin accessibility (Fig. 5B, Pearson correlation $\left.r=-0.86, p<1 \times 10^{-300}\right)$, with regions showing the largest decreases in mCG methylation also showing the largest increases in accessibility and regions showing the largest increases in $\mathrm{mCG}$ methylation also showing the largest decreases in accessibility. Thus, there is a strong correlation between mCG DNA methylation state and chromatin accessibility in differentiating lens cells. 


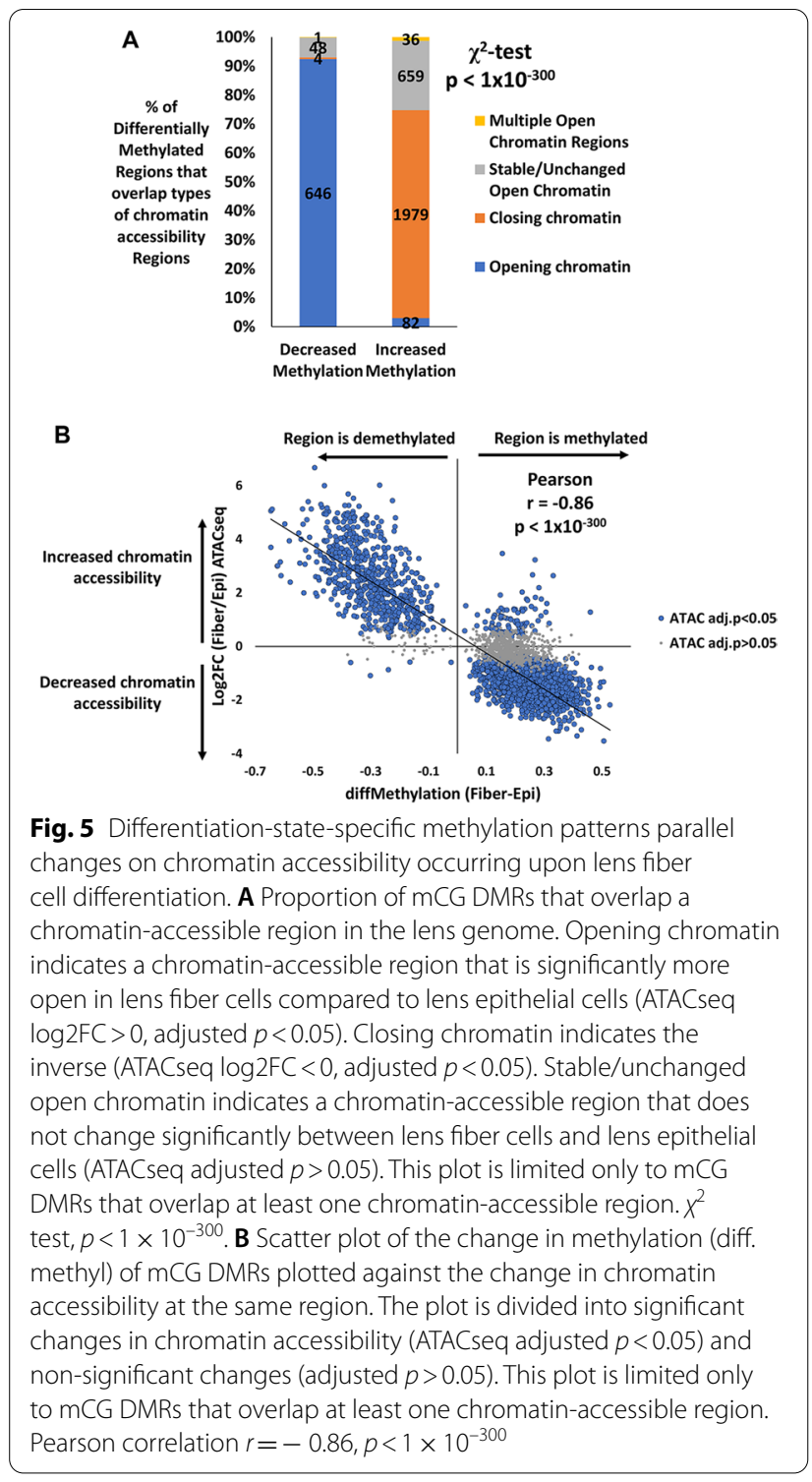

\section{Combined analysis reveals strong correlations between DNA methylation, chromatin accessibility and gene regulation during lens cell differentiation} Integration of bisulfite sequencing, ATACseq, and RNAseq data comparing lens epithelial cells and fiber cells during lens differentiation, revealed 1219 sites in gene bodies and promoters of differentiation state-specific genes that also have significant changes in DNA methylation and chromatin accessibility (Fig. 6A, B, Additional file 12: Table S8A). The combined analysis reveals that 164 sites within gene bodies or promoters of fiber cell genes exhibit decreased methylation and increased chromatin accessibility. One hundred and thirty-five fiber cell preferred genes contained at least one demethylated DNA region that also exhibited increased chromatin accessibility. Additionally, the analysis revealed that 843 identified sites within gene bodies or promoters of epithelial cell preferred genes exhibit increased methylation and decreased chromatin accessibility in fiber cells, and 467 epithelial cell preferred genes contain at least one methylated region that also exhibits decreased chromatin accessibility. A Chi-squared test confirms the significant association between differentially methylated $\mathrm{mCG}$ sites in differentially accessible chromatin regions and corresponding gene expression changes (Fig. 6B, Chi-square $\left.p<1 \times 10^{-76}\right)$. A similar analysis was performed for the 149 sites in promoters of differentiation state-specific genes that also show significant changes in DNA methylation and chromatin accessibility (Fig. 6C, D, Additional file 12: Table S8B). Similar to the results above, 22 sites within promoters of fiber cell preferred genes exhibit decreased methylation and increased chromatin accessibility. 22 fiber cell preferred genes contained at least one demethylated DNA region that also exhibited increased chromatin accessibility. Additionally, the analysis revealed that 106 identified sites within promoters of epithelial cell preferred genes exhibited increased methylation and decreased chromatin accessibility in fiber cells. 91 epithelial cell preferred genes contained at least one methylated region that also exhibited decreased chromatin accessibility in fiber cells. A Chi-squared test confirmed a significant association between differentially methylated mCG sites in differentially accessible chromatin regions at putative promoters $(-2 \mathrm{~kb}$ upstream from the transcription start site) and corresponding gene expression changes (Fig. 6D, Chi-square $p<1 \times 10^{-13}$ ). These data suggest a direct relationship between DNA methylation and chromatin accessibility both of which are correlated with specific changes in gene expression occurring during the differentiation of lens epithelial cells into lens fiber cells.

This relationship extends to multiple genes with important lens functions. Both of the crystallin genes CRYBB1 and CRYBA4 [55-58] share the same promoter region, a feature also seen in mouse and human genomes $[59,60]$, and both have at least $3 \times$ greater expression levels in fiber cells compared to epithelial cells (Fig. 6E). The shared promoter region contains one differentially methylated region with significantly lower methylation levels in fiber cells compared to epithelial cells. This demethylated region is also contained within an open chromatin region with increased chromatin accessibility in fiber cells compared to epithelial cells. Another example is the lens fiber cell-specific transcription factor HSF4 [61, 62] (Fig. 6F) that exhibits one differentially methylated region in the promoter and one 
in the fifth intron of the gene body. Both have significantly lower methylation levels, and both are also contained within an open chromatin region with increased chromatin accessibility in fiber cells compared to epithelial cells. There is also an open chromatin region partially contained within the sixth intron and sixth exon that exhibits increased chromatin accessibility in fiber cells compared to epithelial cells and also appears to exhibit lower methylation levels in fiber cells relative to epithelial cells. However, this region was not identified as a statistically significant differentially methylated region by the DSS analysis software. Another example is $\mathrm{NOTCH} 2$, a receptor that upon conditional mutation results in a cataract in mice [63]. The Notch signaling pathway has been previously established as an essential pathway for lens differentiation [64]. $\mathrm{NOTCH} 2$ (Fig. 6G) is expressed at significantly lower levels in fiber cells and contains one differentially methylated region in the promoter and one in the second intron of the gene body. Both regions have significantly higher methylation levels in fiber cells. The methylated region in the promoter is contained within an open chromatin region with unchanged chromatin accessibility (ATACseq $q>0.05$ ) and the methylated region in the second intron is contained within an open chromatin region with decreased chromatin accessibility in fiber cells (ATACseq $\log 2 \mathrm{FC}<0, q<0.05$ ). The genome tracks used for Fig. 6 can also be found at (http:// genome.ucsc.edu/s/jdisatha/galGal6_methylome_Lens) where interested readers can also search for any gene of interest to visualize the presence or absence of nearby differentially methylated regions and differential chromatin accessibility regions between lens epithelial and fiber cells.

\section{Identification of transcription factor binding sites in differentially methylated DNA regions}

To explore the relationship between representation of transcription factor consensus sequences in regions with altered DNA methylation and altered gene expression, transcription factor binding motifs significantly overrepresented in differentially methylated DNA regions were correlated with differential gene expression levels in lens epithelial and fiber cells using the AME tool from MEME-suite $[65,66]$ (Fig. 7A, B). Regions of DNA with significantly greater methylation in fiber cells relative to epithelial cells and mapped to promoters or gene bodies of epithelial cell genes contained, among others, the binding motifs of ARNT:HIF1a, RBPJ, MYCN, and MAX:MYC (Fig. 7A, Additional file 13: Table S9A). Many of the enriched binding motifs are from transcription factors with well-established roles in regulation of lens gene expression, lens development, and differentiation (Additional file 13: Table S9) [44, 64, 67-89]. Consistently, previous studies showed HIF1 to be a major regulator of lens gene expression [44], RBPJ is involved in early lens development $[64,87]$, and both $\mathrm{c}-\mathrm{Myc}$ and $\mathrm{n}$-Myc have established roles in lens cell proliferation and differentiation $[70,86]$. Conversely, regions

\footnotetext{
(See figure on next page.)

Fig. 6 Multiomics analysis reveals strong correlations between DNA methylation, chromatin accessibility and gene regulation during lens cell differentiation. A Scatter plot of the change in methylation (diff. methyl) of mCG DMRs mapped to the promoter or genebody of a DEG plotted against the change in chromatin accessibility. Red indicates a mCG DMR that is mapped to an upregulated/fiber cell gene. Blue indicates a mCG DMR that is mapped to a downregulated/epithelial cell gene. This plot is limited only to mCG DMRs that are mapped both to a chromatin-accessible region and either the promoter or genebody of a DEG. B Proportion of differentially methylated regions contained within the promoter or gene body of a DEG (upregulated/fiber cell gene or downregulated/epithelial cell gene) that is also contained within a differentially accessible chromatin region. Each site is categorized based on whether it has (1) increased or decreased mCG methylation during lens differentiation; (2) increased or decreased chromatin accessibility during lens differentiation, and (3) if the site is in the promoter or gene body of an epithelial cell preferred gene (RNAseq $\log 2 \mathrm{FC}<-0.4, q<0.05$ ) or a fiber cell preferred gene (RNAseq $\log 2 \mathrm{FC}>0.4, q<0.05$ ). This chart is limited only to mCG DMRs that are mapped to a differentially accessible chromatin region (ATACseq $q<0.05$ ) and either the promoter or genebody of a DEG. Chi-square test $p<1 \times 10^{-43}$. C Same as $\mathbf{A}$ but limited to the change in methylation (diff. methyl) of mCG DMRs that are mapped only to the promoter of a DEG and a chromatin-accessible region. Red indicates a mCG DMR that is mapped to an upregulated/fiber cell gene. Blue indicates a mCG DMR that is mapped to a downregulated/epithelial cell gene. D Same as B but limited to the change in methylation (diff. methyl) of mCG DMRs that are mapped only to the promoter of a DEG that is also in a differentially accessible chromatin region (ATACseq $q<0.05$ ). Chi-square test $p<1 \times 10^{-9}$. E Galgal6 UCSC genome browser track encompassing CRYBB1 and CRYBA4. Black bent arrows indicate transcription start sites. Vertical light blue highlighted column indicates the genomic region within the promoter region of both CRYBB1 and CRYBA4 that contains a mCG DMR that is significantly demethylated in fiber cells compared to epithelial cells. Also shown are tracks of the relative mCG methylation levels in epithelial cells (D13Epi_4_CG.bw) and fiber cells (D13_Fib_4_CG.bw). Tracks of ATACseq peak intensity from lens epithelial and fiber cells. Taller and wider peaks represent increased chromatin accessibility at the corresponding genomic region. Also shown are the relative gene expression changes expressed as fold change FPKM values of CRYBB1 and CRYBA4 in fiber cells compared to epithelial cells. F Same as $\mathbf{C}$ but for HSF4. Two mCG DMRs are shown. One in the promoter region (left) and one in the genebody (right). The relative gene expression changes expressed as fold change FPKM values of HSF4 in fiber cells compared to epithelial cells. G Same as $\mathbf{C}$ but for NOTCH2. Two mCG DMRs are shown. One in the promoter region (left) and one in the genebody (right). The relative gene expression changes of NOTCH2 are expressed as fold change FPKM values in epithelial cells compared to fiber cells
} 


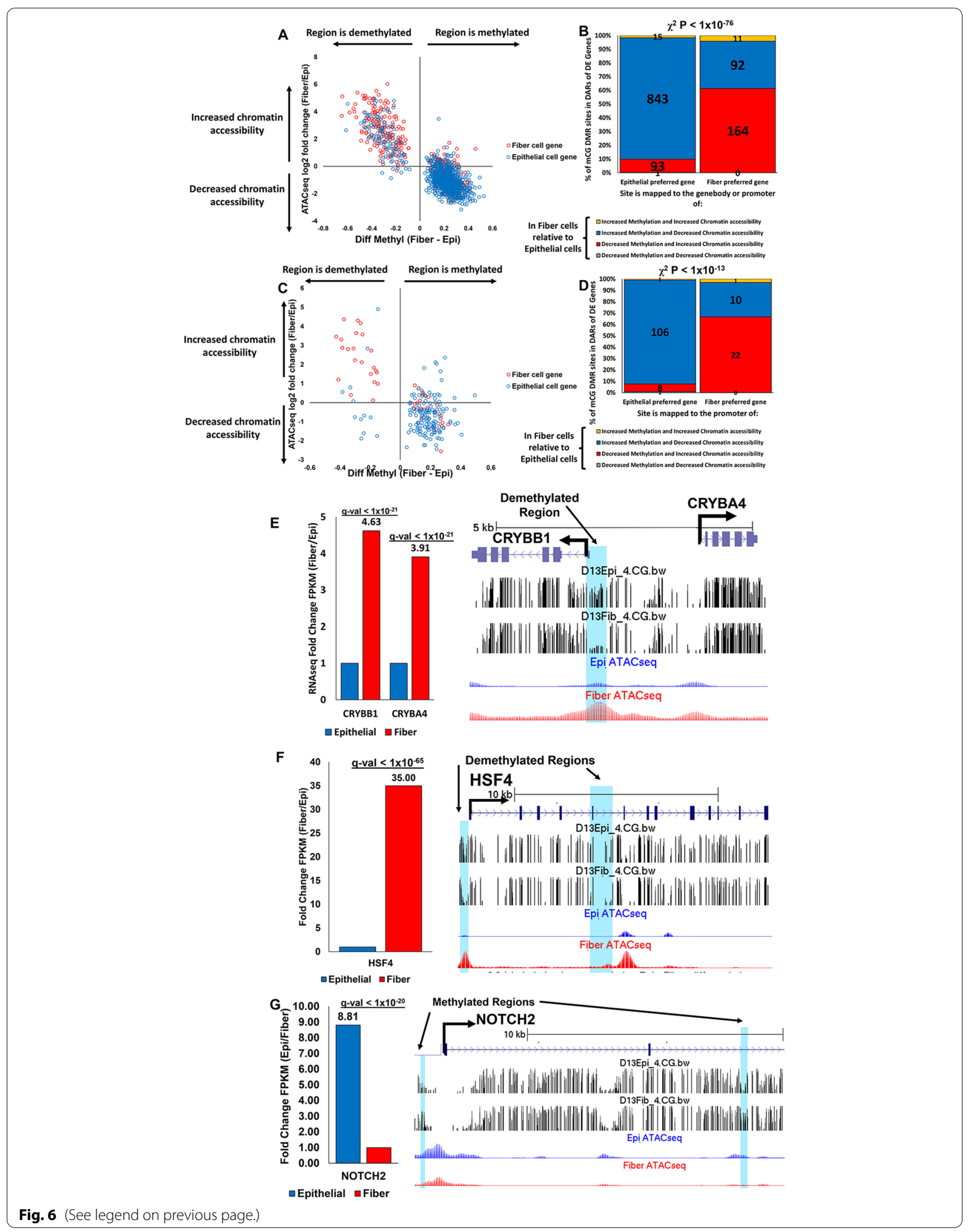


Enriched Transcription Factor binding motifs found within mCG DMRs in promoters or genebodies of Differentially expressed genes

A. At Methylated mCG DMRs of Epithelial Genes
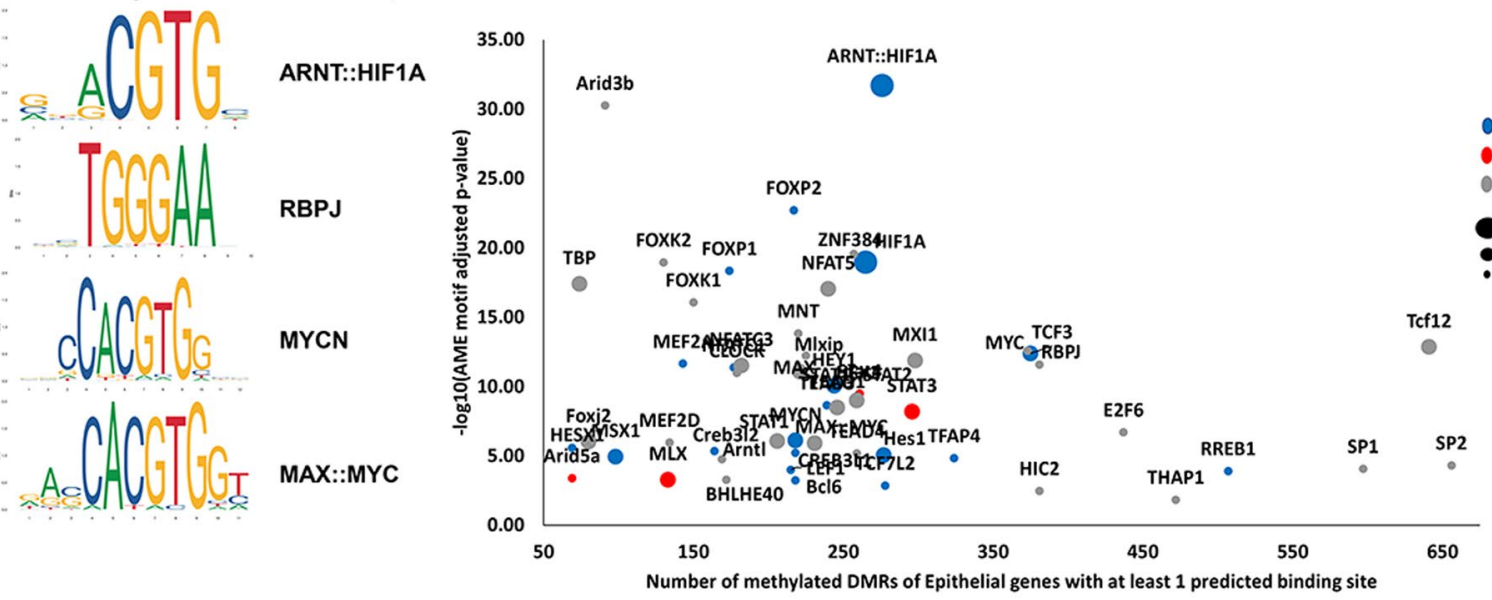

B. At Demethylated mCG DMRs of Fiber Genes
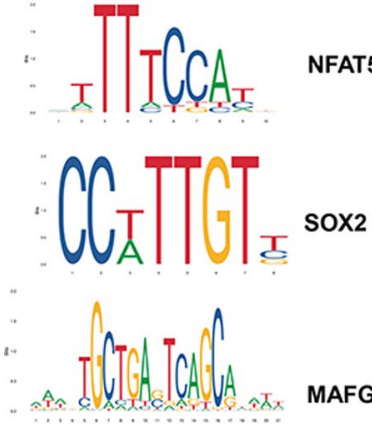

MAFG

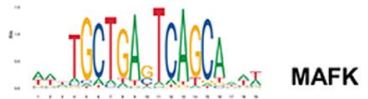

$$
\text { }
$$

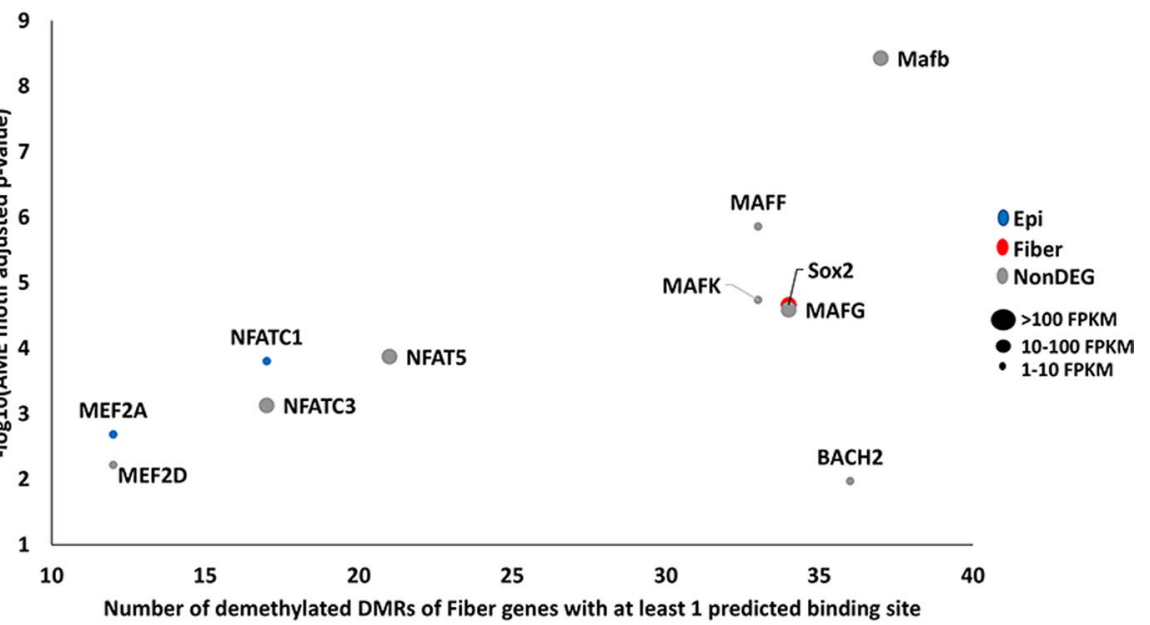

Number of demethylated DMRs of Fiber genes with at least 1 predicted binding site

Fig. 7 Identification of transcription factor binding sites in differentially methylated DNA regions. A DNA sequences within Genomic regions with (1) significantly higher methylation in lens fiber cells compared to lens epithelial cells and (2) found in the genebodies or promoters of genes with decreased expression levels in fiber cells compared to epithelial cells were analyzed to find significantly enriched transcription factor binding motifs. Scatterplot shows a plot of the $-\log 10$ (adjusted $p$ value) of significantly detected transcription factor motifs identified using the AME tool versus the number of downregulated/epithelial cell genes that have at least one binding site within a methylated region identified by the FIMO tool. Only transcription factors encoded by genes that have a total transcript expression level (sum of average Epi and Fiber FPKM) of at least 1 FPKM are reported (Additional file 13: Table S9A). The color of each datapoint also indicates whether the gene encoding the transcription factor is more highly expressed in epithelial cells (blue) (log2-fold change FPKM $<-0.4, q<0.05$ ), fiber cells (red) (log2-fold change FPKM $>0.4, q<0.05$ ), or there is no significant differences in gene expression levels between epithelial and fiber cells (grey) (Additional file 13: Table S9A). The size of each datapoint corresponds to the total transcript expression level for each transcription factor. Select transcription factor consensus sequence logos from JASPAR database are shown. B Same as $\mathbf{A}$ but for DNA sequences in genomic regions with (1) significantly lower methylation in lens fiber cells compared to lens epithelial cells and (2) found in the genebodies or promoters of genes with increased expression levels in fiber cells compared to epithelial cells

of DNA that exhibited decreased methylation in fiber cells and are contained within putative promoters of genes preferentially expressed in fiber cells contained, among other binding sequences, the consensus site for transcription factor NFAT5, SOX2, and the MAF family of transcription factors (Fig. 7B, Additional file 13:
Table S9B). Consistently, previous studies revealed a role for NFAT5 in the hyperosmotic stress response in human lens epithelial cells [85], SOX2 is a well-established transcription factor required for lens development [90], and the MAF family of transcription factors are known regulators of lens gene expression and lens 
development [76, 77, 79-81]. The data suggest that changes in DNA methylation within the identified regions regulate the ability of specific lens transcription factors to control gene expression changes during lens cell differentiation.

Transcription factor abundance is one of many factors that control the rate of transcription of target genes [91]. Although the present study does not reveal the relative protein abundances of transcription factors, the analysis does identify the relative mRNA expression levels of the transcription factors with the most enriched consensus sequences found within differentially methylated regions of DNA. Many of the highly expressed transcription factors identified in Fig. 7 and Additional file 13: Table S9 (total FPKM > 12) such as HIF1A [44, 92], HEY1 [88], STAT3 [69], SOX2 [82], and MAFB [76, 77, 79, 80] have known functions in lens development and differentiation (Additional file 13: Table S9). In contrast, the transcription factors with low expression levels (total FPKM $<5$ ) such as MAFF, Arid5a, TEAD4, and HIC2 (Additional file 13: Table S9) do not yet have any known functions in the regulation of lens structure, homeostasis, or gene expression. Although we cannot rule out the potential role of lowly expressed transcription factors in the regulation of the identified differentially methylated genes, the data suggest that transcription factors that are (1) highly expressed, and (2) have a highly enriched consensus sequence in the identified differentially methylated regions (high - log10 AME motif adjusted $p$ value and high number of predicted target genes, Fig. 7, Additional file 13: Table S9) likely play a major role in the regulation of lens gene expression via binding to differentially methylated regulatory elements during lens differentiation.

Interestingly, the SOX2 gene is more highly expressed and demethylated in fiber cells relative to epithelial cells (Additional file 13: Table S9B). Analysis of transcription factor binding sequences revealed that the consensus sequence for SOX2 is enriched in genes that are more highly expressed and demethylated in fiber cells relative to epithelial cells. Thus, both SOX2, and its predicted target fiber cell genes (Additional file 14: Table S10A) have increased expression and decreased methylation during lens cell differentiation. Conversely, the genes for RREB1, TCF3, FOXP1, CREB3L2, HIF1a, BCL6, MEF2A, MSX1, LEF1, CREB3L1, HEY1, TCF7L2, and NFATC1 have significantly decreased expression levels and are methylated in fiber cells relative to epithelial cells (Additional file 13: Table S9A). Analysis of transcription factor binding sequences revealed that the consensus sequences for these transcription factors are enriched in genes with decreased expression and increased methylation in fiber cells relative to epithelial cells. Thus, both the identified transcription factors and their predicted target epithelial cell genes (Additional file 14: Table S10B) have decreased expression and increased methylation during lens cell differentiation. The data suggest a role for DNA methylation in controlling both the availability and accessibility of transcription factors during lens differentiation.

\section{Discussion}

Although the role of CG methylation (mCG) in gene silencing is well-established, few studies have examined its potential role in control of cellular differentiation. In the present study, we sought to establish a role for CG methylation in control of gene expression levels required for differentiation of immature lens epithelial cells into mature fiber cells conferring the adult structure and transparent function of the eye lens. The lens is a wellcharacterized model for cellular differentiation and previous studies have shown that differentiation state-specific changes in gene expression $[43,93]$ and chromatin accessibility $[32,47]$ characterize the differentiation of lens epithelial cells into lens fiber cells. Here, we employed bisulfite sequencing to interrogate the potential for $\mathrm{mCG}$ methylation in regulating chromatin accessibility, gene expression, and hence lens cell differentiation.

Analysis of whole genome bisulfite sequencing data identified 7621 genomic regions exhibiting differentiation state-specific differences in mCG levels between undifferentiated lens epithelial and differentiated fiber cells. Sites exhibiting increased mCG methylation at promoters and genebodies had a strong correlation with decreased gene expression levels in lens fiber cells and sites exhibiting decreased mCG methylation at promoters and genebodies had a strong correlation with increased gene expression levels in lens fiber cells (Pearson correlation $r=-0.37, p<1 \times 10^{-42}$ ).

Interrogation of the relationship between mCG DNA methylation levels and chromatin accessibility changes determined by ATAC-seq revealed that sites exhibiting decreased mCG methylation had a strong correlation with increased chromatin accessibility in lens fiber cells and sites exhibiting increased mCG methylation had a strong correlation with decreased chromatin accessibility in lens fiber cells (Pearson correlation $r=-0.86$, $p<1 \times 10^{-300}$ ).

Many of the identified genes exhibiting altered mCG DNA methylation changes in association with corresponding changes in chromatin accessibility and differentiation state-specific gene expression have established requirements for specialized lens functions including lens cell structure, homeostasis and cell signaling (Additional file 15: Table S11) [41, 44, 56, 62-64, 75, 82, 92, 94-119, 119-184]. For instance, the lens crystallins, CRYBB2, CRYBB1, CRYBA4, CRYGN, CRYBB3, and CRYBA1 are all critical for lens fiber cell transparency. 
With the exception of CRYBB2, all these genes are more highly expressed in fiber cells. CRYBA1, CRYBB2, and CRYBB3 are more highly methylated in fiber cells while conversely CRYBA4, CRYBB1, and CRYGN are demethylated in fiber cells, showing the complexity of this level of control. However, the genes in each group are coordinately expressed through epithelial to fiber cell differentiation (Ma et al., submitted). $\delta$-crystallin (ASL1) is the most highly expressed crystallin in chicken $[185,186]$ and is more highly expressed in fiber cells compared to epithelial cells (Additional file 7: Table S3). However, there were no detectable changes in mCG DNA methylation in the promoter nor genebodies of these genes. This suggests that the differential expression of $\delta$-crystallin is likely controlled by a mechanism independent of DNA methylation changes. Analysis of the ATACseq data from [32] reveals that the genebody and promoter of the $\delta$-crystallin gene (ASL1) contains 6 regions of chromatin with increased accessibility in fiber cells compared to epithelial cells. Thus, it is likely that $\delta$-crystallin expression is regulated by chromatin accessibility changes independent of DNA methylation changes.

Other non-crystallin genes important for lens cell homeostasis, structure, and transparency also exhibited altered mCG DNA methylation changes in association with corresponding changes in chromatin accessibility and differentiation state-specific gene expression. An example is HSF4 that is a fiber cell-specific transcription factor that regulates nuclear degradation during lens fiber cell differentiation $[95,187,188]$. Also included are the beaded filament proteins BFSP1 and BFSP2 that are well-established lens fiber cell structural genes [177]. NOTCH1, NOTCH2, HES5, and HEY1 are all components of the NOTCH signaling pathway which plays a major role in lens epithelial cell function and differentiation into fiber cells $[63,64,189,190]$. Finally, the hypoxic environment of the lens itself has been shown to be critical for initiation of lens differentiation [31]. Consistent with a role for DNA methylation in regulating hypoxia-associated gene expression and lens properties, VEGF, a hypoxia-regulated lens gene involved in lens development $[44,191]$ and the hypoxia-regulated transcription factor HIFla that controls lens fiber cell gene expression and the degradation of non-nuclear organelles that occurs during mature lens formation $[44,67]$ were identified as differentially methylated during lens cell differentiation.

A majority of lens-related function genes (89 of 112 genes, 79.5\%) (Additional file 15: Table S11) had expression level changes associated with the inverse change in methylation levels consistent with the analysis performed on the entire set of 1285 differentially expressed genes with changes in methylation levels (973 of 1285 genes, 75.7\% Fig. 4, Additional file 9: Table S5). Additionally, although a majority of the identified differentially expressed genes with differentially methylated regions do not yet have a reported function in the lens (1173 of 1285 genes, 91.3\%), it is likely that these genes have some function in the lens but to-date these potential functions are not yet well-characterized or reported in the literature.

In addition to individual genes, many of the identified processes and pathways exhibiting an association between gene expression, and DNA methylation (Additional file 3: Figure S3, Additional file 10: Table S6) have well-established functions in the lens such as hedgehog signaling [192, 193], EMT [194, 195], UV response [196, 197], Notch signaling [63, 64, 139], cell cycle control [119, 198-200], hypoxia [44, 92], IFN-gamma signaling [201, 202]. The present data suggest that this epigenetic regulatory mechanism plays a role in these critical lens processes through changes in differentiation state-specific DNA methylation at potential cis-regulatory sequences.

Analysis of transcription factor binding sequences contained within DNA regions exhibiting differentiation state-specific DNA methylation changes revealed a wide variety of established and novel enriched transcription factor binding sequences (Additional file 13: Table S9) including those for HIF1a that has been previously established to be an important regulator of differentiation state-specific gene expression in the lens [44, 67], SOX2 which has a well-established role in lens development $[82,203,204]$, and TCF3 that has yet to be evaluated for its potential lens function. Intriguingly, several of the genes encoding the identified transcription factors with enriched consensus sequences also had significant changes in methylation levels and gene expression levels in fiber cells compared to epithelial cells (Additional file 13: Table S9). Additionally, analysis of transcription factor binding sequences also revealed other enriched binding sequences for transcription factors that have previously established lens functions (Additional file 13: Table S9). These include the MAF family of transcription factors MAFB, MAFK, and MAFG which are known to regulate lens gene expression during development and differentiation [76, 77, 79-81], n-myc and c-myc [70, 86], and the NOTCH transcription factors RBPJ, and HES1 [64, 71, 87]. Some of the identified transcription factors may be unable to bind to chromatin due to DNA methylation reducing the accessibility to that site. This mechanism has been suggested in other studies $[8,14-18]$. Therefore, it is likely that the transcription factors identified in Fig. 7A and Additional file 13: Table S9A are important for the expression of genes in epithelial cells. Then during differentiation and the formation of lens fiber cells, the transcription factor binding sites likely become 
obstructed due to increased mCG DNA methylation thus inhibiting the ability of these transcription factors to induce epithelial cell genes in the fiber cells. In contrast, it is likely that the transcription factors identified in Fig. 7B and Additional file 13: Table S9B are important for the increased expression of genes in fiber cells. During differentiation, these transcription factor binding sites are more accessible due to decreased mCG DNA methylation thus allowing the identified transcription factors to induce expression of genes in the fiber cells. The data suggest a role for DNA methylation in controlling the accessibility of transcription factors to predicted regulatory elements to control gene expression changes during lens differentiation. Additionally, many of the genes encoding the identified transcription factors have significant changes in methylation in their respective promoters and genebodies that are associated with significant changes in expression levels of these transcription factors during lens differentiation. The data suggest that DNA methylation may also control the availability of these transcription factors by regulating the expression of these transcription factors.

MYC (c-myc) a transcription factor that regulates lens cell proliferation during lens development [86] is one transcription factor predicted to bind to regions of DNA with increased mCG DNA methylation of genes with decreased expression levels in lens fiber cells compared to epithelial cells (Fig. 7A, Additional file 13: Table S9A). A previous study has shown that MYC interacts with the DNA methyltransferase DNMT3A to directly methylate CG dinucleotides of the CDKN1A, CCND1, and TIMP2 genes in U373 cells [205] leading to decreased expression levels of these genes. Analysis of the present bisulfite sequencing data revealed that CCND1 and TIMP2 contain multiple regions of DNA with increased mCG DNA methylation in lens fiber cells compared to epithelial cells (Additional file 6: Table S2). Consistently, CCND1 is a Wnt signaling gene in lens epithelial cells that is known to regulate the cell cycle and promote lens epithelial cell proliferation [165]. Its expression levels decrease in fiber cells in parallel with cell cycle exit and terminal lens fiber cell differentiation (Additional file 7: Table S3A, Additional file 15: Table S11)[119]. Analysis of the DNA sequences contained within the regions of CCND1 that have increased mCG DNA methylation, revealed 3 sites that had the MYC transcription factor consensus sequence (Additional file 14: Table S10B). These data suggest that the transcription factor MYC (c-myc) could be directing DNMT3A to methylate CCND1 to inhibit its expression, thus promoting cell-cycle exit leading to terminal lens fiber cell differentiation. Further experiments are required to validate the potential regulatory effect of MYC-DNMT3A on CCND1 expression in the lens and to fully elucidate the potential effects on lens epithelial cell-cycle exit followed by lens fiber cell differentiation.

Intriguingly, despite the overall trend of increased global DNA methylation in differentiated lens fiber cells relative to undifferentiated lens epithelial cells, a large number of genes more highly expressed in lens fiber cells exhibited demethylation relative to epithelial cells. These results suggest that regulation of gene expression by methylation and demethylation could both negatively and positively regulate the expression of genes specific for lens epithelial or fiber cells and they implicate differentiation state-specific control by DNA methylases in this coordinate regulation. An examination of expression levels of methylases between undifferentiated epithelial cells and differentiated fiber cells presents DNMT1 and DNMT3A as non-differentially expressed, while DNMT3B is more highly expressed in epithelial cells relative to fiber cells (Additional file 7: Table S3). Additionally, the DNA demethylases TET2, and TET3 are not differentially expressed, while TET1 is more highly expressed in epithelial cells relative to fiber cells (Additional file 7: Table S3). Of these DNA methylation genes, the DNMT3A genebody and TET2 promoter have increased mCG DNA methylation while the TET1 promoter has decreased mCG DNA methylation in fiber cells relative to epithelial cells (Additional file 6: Table S2). Consistently, lens-specific deletion of DNMT1 results in apoptosis of lens epithelial cells, abnormal lens fiber cell morphology, and specific changes in lens gene expression [206]. Correspondingly, HIF1a which was detected to be methylated and silenced during lens cell differentiation in the present study exhibited increased expression upon DMNT1 deletion in the lens [206] suggesting a role for DNMT1 in controlling HIF1a expression levels. Consistent with DNMT1 playing a general role in the regulation of cell differentiation, overexpression of DNMT1 in breast cancer, pituitary adenomas, and B-cell lymphoma resulted in alteration of both CG methylation and gene expression [207-209].

The integration of bisulfite sequencing and RNAseq data revealed an inverse relationship between DNA methylation levels and gene expression during lens cell differentiation. This negative correlation has also been observed in other important studies in multiple species and other tissues including human trophoblast differentiation [23], myogenic differentiation [21], umbilical cord blood derived mononuclear cells to endothelial cell differentiation [210], adipogenesis [22], and chondrocyte hypertrophic differentiation [24]. Of the 1285 differentially expressed genes that contained at least 1 
differentially methylated region within the genebody or promoter (Additional file 9: Table S5A-D), a majority (974 genes, $75.8 \%$ ) contained differentially methylated regions only within the genebody, while 154 genes (12.0\%) contained differentially methylated regions only within the promoter, and 157 genes (12.2\%) contained differentially methylated regions in both the promoter and genebody. A Pearson correlation analysis comparing the DNA methylation levels and gene expression changes for these subsets of genes revealed that genes with differentially methylated regions in both the promoter and genebody are more inversely correlated with gene expression (Pearson $r=-0.49$ ) compared to genes with differentially methylated regions only in the promoter (Pearson $r=-0.43$ ), or only in the genebody (Pearson $r=-0.35$ ). The data reveal a small variation that suggests methylation changes in the promoter may be more closely correlated with gene expression changes compared to methylation changes in the genebody. However, genes with methylation changes in both the genebody and promoter are even more closely correlated with gene expression changes.

The integration of bisulfite sequencing and ATACseq data also revealed an inverse relationship between DNA methylation levels and chromatin accessibility at differentially methylated regions during lens cell differentiation. This negative correlation between DNA methylation and chromatin accessibility has also been observed in multiple other studies in a variety of species and tissues [211-213]. Of the 3455 differentially methylated regions that are contained within open chromatin regions (Additional file 11: Table S7), a majority $(2690,77.9 \%)$ are within genebodies and a minority $(237,6.9 \%)$ are within putative promoters $(-2 \mathrm{~kb}$ from TSS). The remaining 528 differentially methylated regions in open chromatin are either mapped to intergenic regions or overlap both the promoter and genebody. Pearson correlation analysis revealed that the methylation changes at the 2690 differentially methylated regions within open chromatin at genebodies are more negatively correlated with changes in chromatin accessibility (Pearson $r=-0.87$ ) compared to methylation changes at the 237 differentially methylated regions within open chromatin at putative promoters (Pearson $r=-0.80$ ). The data reveal a small variation that suggests that methylation changes in the genebody are more closely correlated to chromatin accessibility changes compared to methylation changes in the promoter.

Interestingly, integration of the bisulfite sequencing, ATACseq, and RNAseq data revealed 135 genes preferentially expressed in fiber cells that also exhibited at least one genomic site with decreased mCG DNA methylation and increased chromatin accessibility. Conversely, there were 467 genes preferentially expressed in epithelial cells that also exhibited at least one genomic site with increased mCG DNA methylation and decreased chromatin accessibility. While they represent a minority of all differentially expressed genes (602 of 4582, 13.14\%), within this group there is a strong association between epigenetic regulation of differentiation state-specific gene expression via DNA methylation and chromatin accessibility changes during lens cell differentiation. Further, although a majority of differentially expressed genes with differentially methylated regions exhibited an inverse relationship between mCG DNA methylation levels and gene expression changes (973 genes, Fig. 4B), a minority of genes (312) exhibited a positive correlation. This has also been seen in other studies $[214,215]$ and it is well known that the DNA methylation and chromatin accessibility landscapes do not always follow the inverse correlation with gene expression, implying that methylation is only one of multiples levels of transcriptional control [216]. Finally, only 1285 of the 4582 differentiation state-specific genes exhibited significantly altered mCG DNA methylation levels in the promoter or gene body. This observation suggests that a majority of gene expression changes during lens cell differentiation are regulated by alternative mechanisms independent of direct DNA methylation changes at potential regulatory regions. An analysis of the ATACseq data obtained from [217] revealed that 2178 of the 3297 (66.1\%) differentiation state-specific genes without changes in mCG methylation contained at least one region of altered chromatin accessibility between lens epithelial and fiber cells. This suggests that chromatin accessibility changes are one likely regulatory mechanism controlling the expression of those genes that did not display mCG DNA methylation changes between lens epithelial and fiber cells.

The integration of bisulfite sequencing data, RNAseq data, and ATACseq data revealed that 717 differentially expressed genes had at least 1 differentially methylated region contained within a region of altered chromatin accessibility between lens epithelial and fiber cells (ATACseq $q<0.05$, Additional file 12: Table S8). This suggests that both mCG DNA methylation changes and chromatin accessibility changes regulate the expression of these differentiation state-specific genes. However, it cannot be discerned from the present data whether DNA methylation changes are primary or secondary to chromatin accessibility changes regarding regulation of gene expression during lens differentiation. It is possible that DNA methylation changes could precede and regulate chromatin accessibility changes [218]. Or changes in chromatin accessibility could alter accessibility of DNA methyltransferases to target sites leading to altered DNA methylation patterns [216, 219]. Further experiments 
are required to fully elucidate the dynamic epigenetic landscape of the lens, the potential causal relationship between DNA methylation changes and chromatin accessibility changes, and subsequent control of gene expression during lens differentiation.

Although many differentially methylated mCG regions were located within open chromatin regions (3455 of 7621 mCG DMRs), only a small percentage of open chromatin regions contain differentially methylated regions (Additional file 4: Figure S4). This suggests that most chromatin accessibility changes likely occur independently of DNA methylation changes, or perhaps that the methylation background of these genes is set for the eye developmental field before D13 rather than specifically for the epithelial to fiber cell differentiation. Nevertheless, for those genes that are differentially methylated, changes in the level of methylation are a strong predictor of changes in chromatin accessibility and changes in gene expression levels.

A Pearson correlation analysis comparing gene expression changes and methylation changes within open chromatin regions (Additional file 16: Table S12) revealed that mCG methylation changes within regions of chromatin that have significant changes in chromatin accessibility (ATACseq adjusted $p$ value $<0.05$ ) are most negatively correlated with gene expression $(r=-0.49)$ compared to mCG methylation changes within any open chromatin region $(r=-0.44)$ and methylation changes at all DNA regions within the promoter and genebody $(r=-0.37$, Fig. 4A). Additionally, limiting the analysis to only promoter mCG methylation changes within regions of chromatin with significant changes in chromatin accessibility revealed the most negative correlation with gene expression $(r=-0.57)$. Although they make up a small proportion of all differentially expressed genes (133 of 4582, $2.9 \%)$, they nevertheless represent the set of genes that are likely regulated by a combination of DNA methylation changes and chromatin accessibility changes, especially within putative promoters.

\section{Conclusions}

Collectively, these results establish DNA methylation as a mechanism regulating the genes and processes associated with lens cell differentiation and implicate it in alterations in chromatin accessibility and hence the control of gene expression that characterize lens cell differentiation. They also suggest a role for DNA methylation in controlling both the availability and accessibility of transcription factors during lens differentiation and provide a basis for future studies on the role of epigenetic mechanisms in control of lens cell differentiation. Finally, they provide a general blueprint for studies aimed at identifying the role of DNA methylation in the development and differentiation of more complex tissues.

\section{Methods \\ Microdissection and isolation of embryonic chick lens epithelial and fiber cells}

Lenses were isolated from White Leghorn embryonated chicken eggs (Charles River Laboratories, Storrs, CT) at embryonic developmental stage day 13 (E13). 25 lenses per biological replicate were microdissected into epithelial cells and fiber cells as previously described [92]. Microdissected epithelial and fiber cells from 25 lenses were pooled and stored in CryoStor CS10 cryopreservation media containing 10\% DMSO (Stemcell, Vancouver, Canada) and stored at $-80{ }^{\circ} \mathrm{C}$ as previously described [220].

\section{DNA isolation and whole genome bisulfite sequencing}

Tissue in CryoStor media was thawed on ice, centrifuged at $800 \times g$ for $5 \mathrm{~min}$ and the CryStor removed. DNA was isolated using Qiagen Genomic-tip 20/G along with the Qiagen Genomic DNA buffer set according to the manufacturer's instructions. Bisulfite sequencing was performed by Novogene (Sacramento CA) using an Illumina HiSeqTM2500/MiSeq platform using their standard protocols followed by CASAVA base calling and Trimmomatic read trimming and alignment to the galgal6 reference genome using Bismark software [221].

\section{Identification of methylated cytosines and differentially methylated regions}

Reads mapped to chromosomes $1-30, \mathrm{Z}$, and W were retained. Fifteen-eighteen million methylated cytosines were identified across biological replicates of pooled lens epithelial and fiber cells. Fourteen-sixteen million methylated cytosines were of the mCG type. DSS analysis software based on beta-binomial distribution was used for the identification of DMRs as described previously $[222,223]$ with consideration of the spatial correlation, read depth of the sites, and the variance among biologi$\mathrm{cal}$ replicates. The parameters were smoothing $=$ TRUE, smoothing.span $=200$, delta $=0$, p.threshold $=1 \times 10-5$, minlen $=50, \quad \operatorname{minCG}=3$, dis.merge $=100$, and pct. $\operatorname{sig}=0.5$. 7,621 differentially methylated mCG regions were identified between lens epithelial and fiber cells (Additional file 6: Table S2).

\section{RNA isolation, RNA-sequencing, and identification of differentially expressed genes}

Total RNA was isolated from biological triplicates of microdissected chick lens epithelial and fiber cells using TRIZOL $^{\circledR}$ reagent (Invitrogen, prod no: 15593018) according to the manufacturer's instructions. Libraries 
were prepared following Illumina's TruSeq-strandedtotal-RNA-sample preparation protocol. Paired-end sequencing was performed on Illumina's NovaSeq 6000 platform. Cutadapt [224] was used to remove adaptorcontaminated reads, low quality bases and undetermined bases. Reads were mapped to galgal6 genome (ensemble version 96) using Bowtie 2 [225] and HISAT2 [226]. The mapped reads were assembled using StringTie [227]. Comprehensive transcriptomes were generated using gffcompare and StringTie. The R package edgeR [228] was used to estimate the expression levels of all transcripts and to identify differentially expressed genes $(\log 2$-fold change FPKM $>0.4$ or $<-0.4$ ) with parametric $F$ test comparing nested linear models $(q<0.05) .4,582$ genes were found to be differentially expressed between lens epithelial cells relative to lens fiber cells (Additional file 7: Table S3).

\section{Integrated analysis of bisulfite sequencing and RNA-sequencing data}

Differentially methylated $\mathrm{mCG}$ regions were categorized based on the genomic loci the region was mapped to including promoter $(-2 \mathrm{~kb}$ upstream from transcription start site), utr5, exon, intron, utr3, CGI, CGI shore, or repeat region. Differentially methylated $\mathrm{mCG}$ regions at promoters or gene bodies (utr5, exon, intron, utr3) were compared to the expression pattern of the nearest gene. Since many genes contained more than one differentially methylated $\mathrm{mCG}$ region in the promoter and gene body, the average change in mCG methylation level for all $\mathrm{mCG}$ regions mapped to the promoter and genebody of each gene was calculated (Additional file 9: Table S5). Pearson correlation analysis and Chi-square analysis was conducted to determine the potential correlation and association between average changes in mCG methylation levels and changes in gene expression during lens differentiation from undifferentiated lens epithelial cells to differentiated lens fiber cells (Fig. 4A-D).

\section{Integrated analysis of bisulfite sequencing and ATAC sequencing data}

Genomic coordinates of chick lens open chromatin regions mapped by ATAC sequencing [43] were lifted to galgal6 using UCSC Genome Browser [229] liftover tool. Open chromatin regions were categorized as opening (log2-fold change Fiber/Epi $>0, q<0.05$ ), closing (log2fold change Fiber/Epi $<0, q<0.05$ ) or stable/unchanged $(q>0.05)$ based on data obtained from a previous study of ATAC sequencing on microdissected embryonic chick lens cells at the same developmental stage E13 [217].

Differentially methylated mCG regions identified by whole genome bisulfite sequencing that overlap the genomic coordinates of previously identified open chromatin regions by at least $1 \mathrm{bp}$ are noted in Additional file 11: Table S7. 3455 differentially methylated mCG regions were found in open chromatin regions. Pearson correlation analysis and Chi-square analysis was conducted to determine the potential correlation and association between changes in mCG methylation levels and changes in chromatin accessibility during lens differentiation from undifferentiated lens epithelial cells to differentiated lens fiber cells (Fig. 5A, B).

\section{Approach to integrating bisulfite sequencing, RNA-sequencing, and ATAC sequencing}

Differentially methylated mCG regions identified by whole genome bisulfite sequencing were filtered for both of the following properties: (1) region overlaps an open chromatin region with differentiation state-specific chromatin accessibility (log2-fold change Fiber/Epi $\neq 0$, and $q<0.05$ ) by at least $1 \mathrm{bp}$ and (2) region is contained within the promoter $(-2 \mathrm{~kb}$ upstream of transcription start site) or gene body of a differentially expressed gene (FPKM $\log 2 \mathrm{FC}>0.4$ or $<-0.4$, and $q<0.05$ ). The identified differentially methylated $\mathrm{mCG}$ regions were separated based on whether they mapped to the promoter or gene body of an epithelial cell preferred gene (RNAseq FPKM log2-fold change $<-0.4$, and $q<0.05$ ) or a fiber cell preferred gene (RNAseq FPKM log2-fold change $>0.4$, and $q<0.05$ ). Each region was further sorted into one of four possible combinations: (1) decreased methylation (diff. Methyl $<0$ ) and decreased chromatin accessibility ( $\log 2$-fold change fiber/epi $<0$, and $q<0.05$ ); (2) decreased methylation (diff. Methyl $<0$ ) and increased chromatin accessibility (log2-fold change fiber/epi $>0$, and $q<0.05$ ); (3) increased methylation (diff. Methyl $>0$ ) and decreased chromatin accessibility (log2-fold change fiber/epi $<0$, and $q<0.05$ ), or (4) increased methylation (diff. Methyl $>0$ ) and increased chromatin accessibility (log2-fold change fiber/epi $>0$, and $q<0.05$ ). The resulting data can be found in Additional file 12: Table S8A, B and are visualized in Fig. 6A-D. Chi-square analysis was conducted to determine the potential association between differentially methylated mCG regions within differentially accessible chromatin regions at genebodies and promoters with corresponding gene expression changes between lens epithelial and fiber cells.

\section{Gene ontology and pathway analysis}

The top 200 most highly expressed epithelial cell preferred genes (RNAseq FPKM $\log 2 \mathrm{FC}<-0.4, q<0.05$, ranked from highest to lowest FPKM in epithelial cells) and top 200 most highly expressed fiber cell preferred genes (RNAseq FPKM $\log 2 \mathrm{FC}>0.4, q<0.05$, ranked from highest to lowest FPKM in fiber cells) were each used as separate inputs to the Enrichr tool [52-54] to find 
overrepresented biological processes and pathways associated with lens differentiation state-specific genes. The resulting gene ontology biological processes and MSigDB [230] pathways are reported in Additional file 8: Table S4 and Additional file 2: Figure S2A-D.

The Enrichr tool was also used on the following groups of differentially expressed genes with at least one differentially methylated $\mathrm{mCG}$ region in the putative promoter or genebody: (1) fiber cell preferred genes (RNAseq FPKM $\log 2 \mathrm{FC}>0.4, q<0.05$ ) with an average diff.methyl $<0$ of all differentially methylated $\mathrm{mCG}$ regions mapped to the promoter and genebody of the fiber cell preferred gene; (2) epithelial cell preferred genes (RNAseq FPKM $\log 2 \mathrm{FC}<-0.4, q<0.05$ ) with an average diff.methyl $>0$ of all differentially methylated mCG regions mapped to the promoter and genebody of the epithelial cell preferred gene. The resulting overrepresented gene ontology biological processes and MsigDB pathways are reported in Additional file 10: Table S6A-D and Additional file 3: Figure S3A-D. The same analysis was also conducted for a smaller gene list containing only differentially expressed genes with differentially methylated promoters (Additional file 3: Figure S3E-H, Additional file 10: Table S6E-H).

\section{Transcription factor binding motif analysis}

DNA sequences from differentially methylated mCG regions within the promoter $(-2 \mathrm{~kb}$ upstream from the transcription start site) and genebody of differentially expressed genes were analyzed for enriched transcription factor binding motifs using the AME tool from MEME-suite $[65,66]$. The DNA sequences were separated into two groups: (1) sequences from demethylated $\mathrm{mCG}$ regions (diff.methyl $<0$ ) of fiber cell preferred genes (RNAseq FPKM $\log 2 \mathrm{FC}>0.4, q<0.05$ ); (2) sequences from methylated $\mathrm{mCG}$ regions (diff.methyl $>0$ ) of epithelial cell preferred genes (RNAseq FPKM $\log 2 \mathrm{FC}<-0.4$, $q<0.05)$. Each group was analyzed separately with the AME tool versus a shuffled background according to default settings. The JASPAR nonredundant vertebrate transcription factor motif database [231] was used with the AME tool. All other default settings were kept. The resulting enriched transcription factor binding motifs were filtered to only include transcription factors with an average expression level of at least 1 FPKM as measured by RNAseq (Additional file 7: Table S3). Enriched transcription factor binding motifs for each group of sequences are in Additional file 13: Table S9 and visualized in Fig. 7A, B.

The MEME-suite FIMO tool [232] was used to identify the genomic coordinates of the enriched transcription factor binding sites identified by the AME tool using default settings. The JASPAR nonredundant vertebrate transcription factor motif database [231] was used as the motif input file. Target binding site methylation levels and corresponding gene expression levels for each predicted enriched transcription factor binding site are reported in Additional file 14: Table S10.

\begin{abstract}
Abbreviations
ATAC-seq: Assay for transposase-accessible chromatin sequencing; TSS: Transcription start site; FPKM: Fragments per kilobase of exon per million fragments mapped; DNMTs: DNA methyltransferases; DMR: Differentially methylated region; DEG: Differentially expressed gene.
\end{abstract}

\section{Supplementary Information}

The online version contains supplementary material available at https://doi. org/10.1186/s13072-022-00440-z.

Additional file 1: Figure S1. Additional comparisons of methylation levels between lens fiber cells and lens epithelial cells. A Pearson correlation analysis of biological triplicate samples of bisulfite sequenced genomic DNA from lens epithelial and fiber cells. B Dendrogram clustering of biological triplicate samples of bisulfite sequenced genomic DNA from lens epithelial and fiber cells. C Methylation levels (ratio of mCG/ CG) at genomic regions within $2 \mathrm{~kb}$ of genebodies in lens epithelial and fiber cells. D Percent difference between the distribution of hypermethylated regions (more methylated in fiber cells) versus the distribution of hypomethylated regions (demethylated in fiber cells) at different genomic regions. Positive values indicate the corresponding genomic region contains a greater percentage of all hypermethylated regions than the percentage of all hypomethylated regions. Negative values indicate the inverse.

Additional file 2: Figure S2. Significant pathways and biological processes associated with differentially expressed genes between lens fiber and epithelial cells. A Top $10 \mathrm{GO}$ Biological processes associated with the top 200 most highly expressed epithelial cell genes (RNAseq $\log 2 \mathrm{FC}<-0.4$, adjusted $p<0.05$, ranked from most to least FPKM in epithelial cells). B Top 10 MSigDB Hallmark pathways. Same gene set as A. C Top $10 \mathrm{GO}$ Biological processes associated with the top 200 most highly expressed fiber cell genes (RNAseq $\log 2 \mathrm{FC}>0.4$, adjusted $p<0.05$, ranked from most to least FPKM in fiber cells). D Top 10 MSigDB Hallmark pathways. Same gene set as $\mathbf{B}$.

Additional file 3: Figure S3. Significant pathways and biological processes associated with DEGs with DMRs between lens fiber and epithelial cells. A Top 10 MSigDB Hallmark pathways associated with upregulated/ fiber cell genes (RNAseq $\log 2 \mathrm{FC}>0.4$, adjusted $p<0.05$ ) that also have decreased average methylation levels at DMRs in the promoter and genebody. Blue colored data indicate a statistically significant association adjusted $p<0.05$. B Top $10 \mathrm{GO}$ Biological processes. Same gene set as $\mathbf{A}$. C Top 10 MSigDB Hallmark pathways associated with downregulated/ epithelial cell genes (RNAseq $\log 2 \mathrm{FC}<-0.4$, adjusted $p<0.05$ ) that also have increased average methylation levels at DMRs in the promoter and genebody. Blue colored data indicate a statistically significant association adjusted $p<0.05$. D Top $10 \mathrm{GO}$ Biological processes. Same gene set as $\mathbf{C}$. E Top 10 MSigDB Hallmark pathways associated with upregulated/fiber cell genes (RNAseq $\log 2 \mathrm{FC}>0.4$, adjusted $p<0.05$ ) that also have decreased average methylation levels at DMRs only in the promoter. Blue colored data indicate a statistically significant association adjusted $p<0.05$. F Top 10 GO Biological processes. Same gene set as E. G Top 10 MSigDB Hallmark pathways associated with downregulated/epithelial cell genes (RNAseq $\log 2 \mathrm{FC}<-0.4$, adjusted $p<0.05$ ) that also have increased average methylation levels at DMRs only in the promoter. Blue colored data indicate a statistically significant association adjusted $p<0.05$. H Top 10 GO Biological processes. Same gene set as $\mathbf{G}$.

Additional file 4: Figure S4. Most chromatin-accessible regions do not contain differentially methylated regions. Proportion of 
chromatin-accessible regions that contain differentially methylated regions or no significant changes in methylation levels. Opening chromatin refers to regions with ATACseq $\log 2 \mathrm{FC}>0$, adj. $p<0.05$. Closing chromatin refers to regions with ATACseq $\log 2 \mathrm{FC}<0$, adj. $p<0.05$. Stable/ unchanged chromatin, ATACseq adj. $p>0.05$.

Additional file 5: Table S1. Proportion of methylated cytosines that are $\mathrm{mCG}, \mathrm{mCHG}, \mathrm{mCHH}$ in each sample of lens epithelial and fiber cells.

Additional file 6: Table S2. Differentially methylated mCG regions between lens epithelial and fiber cells.

Additional file 7: Table S3. Differentially expressed genes between lens epithelial cells and fiber cells. $\mathbf{A}$ Epithelial preferred genes (FPKM $\log 2 \mathrm{FC}<-0.4, q<0.05)$, B Fiber preferred genes (FPKM $\log 2 \mathrm{FC}>0.4$, $q<0.05)$. C Non-differentially expressed genes.

Additional file 8: Table S4. Enrichr outputs of GO Biological processes $(\mathbf{A}, \mathbf{C})$ and MSigDB Hallmark pathways (B, D) significantly associated with the differentially expressed genes between lens epithelial cells and fiber cells. A, B Top 200 epithelial cell preferred genes, C, D top 200 fiber cell preferred genes.

Additional file 9: Table S5. Average change in MCG methylation level for all differentially methylated $m C G$ regions mapped to $\mathbf{A}-\mathbf{D}$ the promoters and genebodies of differentially expressed genes, or $\mathbf{E}-\mathbf{H}$ only the promoters of differentially expressed genes. A, E Epithelial cell preferred genes with increased $\mathrm{mCG}$ methylation. B, F Fiber cell preferred genes with decreased $\mathrm{mCG}$ methylation. $\mathbf{C}, \mathbf{G}$ Epithelial cell preferred genes with decreased $\mathrm{mCG}$ methylation. D, H Fiber cell preferred genes with increased mCG methylation.

Additional file 10: Table S6. Enrichr outputs of MSigDB Hallmark pathways (A, C, E, G) and GO biological processes (B, D, F, H) significantly associated with differentially expressed genes containing differentially methylated promoters and/or gene bodies. A, B Epithelial cell preferred genes with increased average promoter and genebody mCG methylation levels in fiber cells. C, D Fiber cell preferred genes with decreased average promoter and genebody mCG methylation levels in fiber cells. E, F Epithelial cell preferred genes with increased average promoter mCG methylation levels in fiber cells. G, $\mathbf{H}$ Fiber cell preferred genes with decreased average promoter $\mathrm{MCG}$ methylation levels in fiber cells.

Additional file 11: Table S7. Differentially methylated $\mathrm{mCG}$ regions that are at least partially contained within open chromatin regions.

Additional file 12: Table S8. Differentially methylated mCG regions that are at least partially contained within open chromatin regions at $\mathbf{A}$ promoters and genebodies of differentially expressed genes, or $\mathbf{B}$ only promoters of differentially expressed genes.

Additional file 13: Table S9. Significantly enriched transcription factor binding motifs found within $\mathbf{A}$ hypermethylated $\mathrm{MCG}$ regions in promoters or genebodies of epithelial cell preferred genes, or $\mathbf{B}$ hypomethylated mCG regions in promoters or genebodies of epithelial cell preferred genes.

Additional file 14: Table S10. Target binding sites of enriched transcription factor binding motifs along with corresponding methylation changes and gene expression changes. Target binding sites of enriched transcription factor motifs from demethylated DMRs of Fiber cell genes (A), and from methylated DMRs of Epithelial cell genes (B).

Additional file 15: Table S11. Genes with established lens functions or associations with cataracts that are differentially expressed and contain differentially methylated regions between lens epithelial and fiber cells.

Additional file 16: Table S12. Pearson correlation analysis comparing gene expression changes and methylation changes within open chromatin regions. The analyses were performed on the following conditions: differentially methylated regions at (1) promoters and genebodies, (2) only promoters, (3) open and closed chromatin, (4) only open chromatin, (5) only open chromatin with significant changes in chromatin accessibility between lens epithelial and fiber cells (ATACseq adj.p-val <0.05).
Acknowledgements

Not applicable.

\section{Authors' contributions}

JD conceived of the studies, performed experiments, analyzed data and participated in writing of the manuscript as part of his requirements for graduating from the Florida Atlantic University Integrative Biology-Biomedical Science PhD program; LB conceived of the studies, performed experiments, analyzed data, participated in writing of the manuscript and in funding acquisition; XJ performed experiments, and analyzed data; ZM performed experiments and analyzed data: JFH conceived of the studies, analyzed data and participated in the writing of the manuscript; MK conceived of the studies, analyzed data, participated in writing the manuscript, was responsible for funding acquisition and directed the work. The authors read and approved the final manuscript.

\section{Funding}

This work was supported by the National Institutes of Health, USA, National Eye Institute, USA, Grant Number EY029708 (MK).

\section{Availability of data and materials}

Raw sequencing reads for the whole genome bisulfite experiment have been deposited at NCBI-GEO series accession number GSE196629. Raw sequencing reads for the RNA-seq experiment have been deposited at NCBI-GEO series accession number GSE196630. ATACseq data were obtained from supplementary files from [32].

\section{Declarations}

\section{Ethic approval and consent to participate}

Not applicable.

\section{Consent for publication \\ Not applicable.}

\section{Competing interests}

Not applicable.

\section{Author details}

'Department of Biomedical Science, Charles E. Schmidt College of Medicine, Florida Atlantic University, Boca Raton, FL, USA. ${ }^{2}$ Ophthalmic Genetics and Visual Function Branch, National Eye Institute, National Institutes of Health, Bethesda, MD, USA.

Received: 18 November 2021 Accepted: 16 February 2022

Published online: 05 March 2022

\section{References}

1. Henning AN, Roychoudhuri R, Restifo NP. Epigenetic control of CD8 + T cell differentiation. Nat Rev Immunol. 2018;18:340-56. https://doi.org/ 10.1038/NRI.2017.146.

2. Mr A, Gk O. Epigenetic control of smooth muscle cell differentiation and phenotypic switching in vascular development and disease. Annu Rev Physiol. 2012;74:13-40. https://doi.org/10.1146/ANNUREV-PHYSI OL-012110-142315.

3. Mortada I, Mortada R. Epigenetic changes in mesenchymal stem cells differentiation. Eur J Med Genet. 2018;61:114-8. https://doi.org/10. 1016/J.EJMG.2017.10.015.

4. Chandler LA, Jones PA. Hypomethylation of DNA in the regulation of gene expression. Dev Biol. 1988;5:335-49.

5. Harrison PR. Molecular mechanisms involved in the regulation of gene expression during cell differentiation and development. Immunol Ser. 1990;49:411-64.

6. Roy S, Kundu TK. Gene regulatory networks and epigenetic modifications in cell differentiation. IUBMB Life. 2014;66:100-9. https://doi.org/ 10.1002/iub.1249.

7. Edwards JR, Yarychkivska O, Boulard M, Bestor TH. DNA methylation and DNA methyltransferases. Epigenetic Chromatin. 2017. https://doi.org/ 10.1186/S13072-017-0130-8. 
8. Pa J. Functions of DNA methylation: islands, start sites, gene bodies and beyond. Nat Rev Genet. 2012;13:484-92. https://doi.org/10.1038/ NRG3230.

9. Moore LD, Le T, Fan G. DNA methylation and its basic function. Neuropsychopharmacology. 2013;38:23-38. https://doi.org/10.1038/NPP. 2012.112

10. Th B, GI V. DNA methyltransferases. Curr Opin Cell Biol. 1994;6:380-9. https://doi.org/10.1016/0955-0674(94)90030-2.

11. Bogdanović $\mathrm{O}$, Lister R. DNA methylation and the preservation of cell identity. Curr Opin Genet Dev. 2017;46:9-14. https://doi.org/10.1016/J. GDE.2017.06.007.

12. Pennings S. DNA methylation, nucleosome formation and positioning Brief Funct Genom Proteom. 2005;3:351-61. https://doi.org/10.1093/ BFGP/3.4.351.

13. Choy JS, Wei S, Lee JY, Chu S, Tan S, Lee T-H. DNA methylation increases nucleosome compaction and rigidity. J Am Chem Soc. 2010;132:1782. https://doi.org/10.1021/JA910264Z.

14. Yizhar-Barnea O, Valensisi C, Jayavelu ND, Kishore K, Andrus C, KofflerBrill T, Ushakov K, Perl K, Noy Y, Bhonker Y, Pelizzola M, Hawkins RD, Avraham KB. DNA methylation dynamics during embryonic development and postnatal maturation of the mouse auditory sensory epithelium. Sci Rep. 2018. https://doi.org/10.1038/S41598-018-35587-X.

15. Saxonov S, Berg P, Brutlag DL. A genome-wide analysis of CpG dinucleotides in the human genome distinguishes two distinct classes of promoters. Proc Natl Acad Sci USA. 2006;103:1412-7. https://doi.org/10. 1073/PNAS.0510310103.

16. Deaton AM, Bird A. CpG islands and the regulation of transcription. Genes Dev. 2011;25:1010-22. https://doi.org/10.1101/GAD.2037511.

17. Bird A. DNA methylation patterns and epigenetic memory. Genes Dev. 2002;16:6-21. https://doi.org/10.1101/GAD.947102.

18. No H, Fg W, Ba B-K. Structural insights into methylated DNA recognition by the C-terminal zinc fingers of the DNA reader protein ZBTB38. J Biol Chem. 2018;293:19835-43. https://doi.org/10.1074/JBC.RA118.005147.

19. Alajem A, Roth H, Ratgauzer S, Bavli D, Motzik A, Lahav S, Peled I, Ram O. DNA methylation patterns expose variations in enhancer-chromatin modifications during embryonic stem cell differentiation. PLoS Genet. 2021. https://doi.org/10.1371/JOURNAL.PGEN.1009498.

20. Li Q, Li N, Hu X, Li J, Du Z, Chen L, Yin G, Duan J, Zhang H, Zhao Y, Wang J, Li N. Genome-wide mapping of DNA methylation in chicken. PLoS ONE. 2011;6:19428. https://doi.org/10.1371/JOURNAL.PONE.0019428.

21. Tsumagari K, Baribault C, Terragni J, Chandra S, Renshaw C, Sun Z, Song L, Crawford GE, Pradhan S, Lacey M, Ehrlich M. DNA methylation and differentiation: HOX genes in muscle cells. Epigenetics Chromatin. 2013. https://doi.org/10.1186/1756-8935-6-25.

22. Lim YC, Chia SY, Jin S, Han W, Ding C, Sun L. Dynamic DNA methylation landscape defines brown and white cell specificity during adipogenesis. Mol Metab. 2016. https://doi.org/10.1016/J.MOLMET.2016.08.006.

23. Gamage TKJB, Schierding W, Hurley D, Tsai P, Ludgate JL, Bhoothpur C, Chamley LW, Weeks RJ, Macaulay EC, James JL. The role of DNA methylation in human trophoblast differentiation. Epigenetics. 2018;13:1154-73. https://doi.org/10.1080/15592294.2018.1549462.

24. Singh P, Lessard SG, Mukherjee P, Rourke B, Otero M. Changes in DNA methylation accompany changes in gene expression during chondrocyte hypertrophic differentiation in vitro. Ann NY Acad Sci. 2021;1490:42-56. https://doi.org/10.1111/NYAS.14494.

25. Menko SA. Lens epithelial cell differentiation. Exp Eye Res. 2002;75:48590. https://doi.org/10.1006/EXER.2002.2057.

26. Bassnett S, Shi Y, Vrensen GFJM. Biological glass: structural determinants of eye lens transparency. Philos Trans R Soc Lond B Biol Sci. 2011;366:1250-64. https://doi.org/10.1098/rstb.2010.0302.

27. Rao PV, Maddala R. The role of the lens actin cytoskeleton in fiber cell elongation and differentiation. Semin Cell Dev Biol. 2006;17:698-711. https://doi.org/10.1016/j.semcdb.2006.10.011.

28. Robinson ML. An essential role for FGF receptor signaling in lens development. Semin Cell Dev Biol. 2006;17:726-40. https://doi.org/10.1016/j. semcdb.2006.10.002.

29. Lovicu FJ, McAvoy JW. Growth factor regulation of lens development. Dev Biol. 2005;280:1-14. https://doi.org/10.1016/J.YDBIO.2005.01.020.

30. Brennan LA, McGreal-Estrada R, Logan CM, Cvekl A, Menko AS, Kantorow M. BNIP3L/NIX is required for elimination of mitochondria, endoplasmic reticulum and Golgi apparatus during eye lens organelle-free zone formation. Exp Eye Res. 2018. https://doi.org/10.1016/j.exer.2018. 06.003.

31. Brennan L, Disatham J, Kantorow M. Mechanisms of organelle elimination for lens development and differentiation. Exp Eye Res. 2021. https://doi.org/10.1016/J.EXER.2021.108682.

32. Disatham J, Chauss D, Gheyas R, Brennan L, Blanco D, Daley L, Menko AS, Kantorow M. Lens differentiation is characterized by stage-specific changes in chromatin accessibility correlating with differentiation state-specific gene expression. Dev Biol. 2019. https://doi.org/10.1016/j. ydbio.2019.04.020.

33. Piatigorsky J. Lens differentiation in vertebrates: a review of cellular and molecular features. Differentiation. 1981;19:134-53. https://doi.org/10. 1111/J.1432-0436.1981.TB01141.X.

34. Audette DS, Scheiblin DA, Duncan MK. The molecular mechanisms underlying lens fiber elongation. Exp Eye Res. 2017;156:41-9. https:// doi.org/10.1016/j.exer.2016.03.016.

35. Chauss D, Basu S, Rajakaruna S, Ma Z, Gau V, Anastas S, Brennan LA, Hejtmancik JF, Menko AS, Kantorow M. Differentiation statespecific mitochondrial dynamic regulatory networks are revealed by global transcriptional analysis of the developing chicken lens. G3. 2014;4:1515-27. https://doi.org/10.1534/g3.114.012120.

36. Cheng C, Nowak RB, Fowler VM. The lens actin filament cytoskeleton: diverse structures for complex functions. Exp Eye Res. 2017;156:58-71. https://doi.org/10.1016/j.exer.2016.03.005.

37. Costello MJ, Brennan LA, Basu S, Chauss D, Mohamed A, Gilliland KO, Johnsen S, Menko AS, Kantorow M. Autophagy and mitophagy participate in ocular lens organelle degradation. Exp Eye Res. 2013;116:14150. https://doi.org/10.1016/j.exer.2013.08.017.

38. FitzGerald PG. Lens intermediate filaments. Exp Eye Res. 2009;88:16572. https://doi.org/10.1016/j.exer.2008.11.007.

39. Mathias RT, White TW, Gong X. Lens gap junctions in growth, differentiation, and homeostasis. Physiol Rev. 2010;90:179-206. https://doi.org/ 10.1152/physrev.00034.2009.

40. Perng M-D, Zhang Q, Quinlan RA. Insights into the beaded filament of the eye lens. Exp Cell Res. 2007;313:2180-8. https://doi.org/10.1016/j. yexcr.2007.04.005.

41. Cvekl A, Zhang $X$. Signaling and gene regulatory networks in mammalian lens development. Trends Genet. 2017;33:677-702. https://doi.org/ 10.1016/j.tig.2017.08.001.

42. Yang C, Yang Y, Brennan L, Bouhassira EE, Kantorow M, Cvekl A. Efficient generation of lens progenitor cells and lentoid bodies from human embryonic stem cells in chemically defined conditions. FASEB J. 2010;24:3274-83. https://doi.org/10.1096/fj.10-157255.

43. Zhao Y, Zheng D, Cvekl A. A comprehensive spatial-temporal transcriptomic analysis of differentiating nascent mouse lens epithelial and fiber cells. Exp Eye Res. 2018. https://doi.org/10.1016/j.exer.2018.06.004.

44. Disatham J, Brennan L, Chauss D, Kantorow J, Afzali B, Kantorow M. A functional map of genomic HIF1a-DNA complexes in the eye lens revealed through multiomics analysis. BMC Genom. 2021. https://doi. org/10.1186/S12864-021-07795-9.

45. Lachke SA, Alkuraya FS, Kneeland SC, Ohn T, Aboukhalil A, Howell GR, Saadi I, Cavallesco R, Yue Y, Tsai AC-H, Nair KS, Cosma MI, Smith RS, Hodges E, Alfadhli SM, Al-Hajeri A, Shamseldin HE, Behbehani A, Hannon GJ, Bulyk ML, Drack AV, Anderson PJ, John SWM, Maas RL. Mutations in the RNA granule component TDRD7 cause cataract and glaucoma. Science. 2011;331:1571-6. https://doi.org/10.1126/science. 1195970.

46. McAvoy JW, Dawes LJ, Sugiyama Y, Lovicu FJ. Intrinsic and extrinsic regulatory mechanisms are required to form and maintain a lens of the correct size and shape. Exp Eye Res. 2017;156:34-40. https://doi.org/10. 1016/j.exer.2016.04.009.

47. Zhao Y, Zheng D, Cvekl A. Profiling of chromatin accessibility and identification of general cis-regulatory mechanisms that control two ocular lens differentiation pathways. Epigenetics Chromatin. 2019. https://doi. org/10.1186/s13072-019-0272-y.

48. Han W, Xue Q, Li G, Yin J, Zhang H, Zhu Y, Xing W, Cao Y, Su Y, Wang $\mathrm{K}$, Zou J. Genome-wide analysis of the role of DNA methylation in inbreeding depression of reproduction in Langshan chicken. Genomics. 2020;112:2677-87. https://doi.org/10.1016/J.YGENO.2020.02.007.

49. Shi J, Xu J, Chen YE, Li JS, Cui Y, Shen L, Li JJ, Li W. The concurrence of DNA methylation and demethylation is associated with transcription 
regulation. Nat Commun. 2021;12:1-12. https://doi.org/10.1038/ s41467-021-25521-7.

50. Ehrlich M, Lacey M. DNA methylation and differentiation: silencing, upregulation and modulation of gene expression. Epigenomics. 2013;5:553-68. https://doi.org/10.2217/EPI.13.43.

51. Benelli M, Franceschini GM, Magi A, Romagnoli D, Biagioni C, Migliaccio I, Malorni L, Demichelis F. Charting differentially methylated regions in cancer with Rocker-meth. Commun Biol. 2021;4:1-15. https://doi.org/ 10.1038/s42003-021-02761-3.

52. Xie Z, Bailey A, Kuleshov MV, Clarke DJB, Evangelista JE, Jenkins SL, Lachmann A, Wojciechowicz ML, Kropiwnicki E, Jagodnik KM, Jeon M, Ma'ayan A. Gene set knowledge discovery with enrichr. Curr Protoc. 2021;1:e90. https://doi.org/10.1002/cpz1.90.

53. Kuleshov MV, Jones MR, Rouillard AD, Fernandez NF, Duan Q, Wang Z, Koplev S, Jenkins SL, Jagodnik KM, Lachmann A, McDermott MG, Monteiro CD, Gundersen GW, Ma'ayan A. Enrichr: a comprehensive gene set enrichment analysis web server 2016 update. Nucleic Acids Res. 2016. https://doi.org/10.1093/nar/gkw377.

54. Chen EY, Tan CM, Kou Y, Duan Q, Wang Z, Meirelles GV, Clark NR, Ma'ayan A. Enrichr: interactive and collaborative HTML5 gene list enrichment analysis tool. BMC Bioinform. 2013. https://doi.org/10.1186/ 1471-2105-14-128.

55. Berry V, lonides A, Pontikos N, Georgiou M, Yu J, Ocaka LA, Moore AT, Quinlan RA, Michaelides M. The genetic landscape of crystallins in congenital cataract. Orphanet J Rare Dis. 2020. https://doi.org/10.1186/ S13023-020-01613-3.

56. Graw J. Genetics of crystallins: cataract and beyond. Exp Eye Res. 2009:88:173-89. https://doi.org/10.1016/J.EXER.2008.10.011.

57. Cvekl A, Ashery-Padan R. The cellular and molecular mechanisms of vertebrate lens development. Development. 2014;141:4432-47. https:// doi.org/10.1242/dev.107953

58. Wistow G. The human crystallin gene families. 2012. http://neibank.nei. nih.gov. Accessed 6 Feb 2019

59. Takai D, Jones PA. Origins of bidirectional promoters: computational analyses of intergenic distance in the human genome. Mol Biol Evol. 2004;21:463-7. https://doi.org/10.1093/MOLBEV/MSH040.

60. Limi S, Zhao Y, Guo P, Lopez-Jones M, Zheng D, Singer RH, Skoultchi Al, Cvekl A. Bidirectional analysis of Cryba4-Crybb1 Nascent transcription and nuclear accumulation of Crybb3 mRNAs in lens fibers. Invest Ophthalmol Vis Sci. 2019;60:234. https://doi.org/10.1167/IOVS.18-25921.

61. Min J-N, Zhang Y, Moskophidis D, Mivechi NF. Unique contribution of heat shock transcription factor 4 in ocular lens development and fiber cell differentiation. Genesis. 2004;40:205-17. https://doi.org/10.1002/ GENE.20087.

62. Fujimoto M, Izu H, Seki K, Fukuda K, Nishida T, Yamada S-I, Kato K, Yonemura S, Inouye S, Nakai A. HSF4 is required for normal cell growth and differentiation during mouse lens development. EMBO J. 2004;23:4297306. https://doi.org/10.1038/SJ.EMBOJ.7600435.

63. Saravanamuthu SS, Le TT, Gao CY, Cojocaru RI, Pandiyan P, Liu C, Zhang J, Zelenka PS, Brown NL. Conditional ablation of the Notch2 receptor in the ocular lens. Dev Biol. 2012;362:219-29. https://doi.org/10.1016/J. YDBIO.2011.11.011.

64. Rowan S, Conley KW, Le TT, Donner AL, Maas RL, Brown NL. Notch signaling regulates growth and differentiation in the mammalian lens. Dev Biol. 2008;321:111-22. https://doi.org/10.1016/j.ydbio.2008.06.002.

65. McLeay RC, Bailey TL. Motif Enrichment Analysis: a unified framework and an evaluation on ChIP data. BMC Bioinform. 2010;11:165. https:// doi.org/10.1186/1471-2105-11-165.

66. Bailey TL, Boden M, Buske FA, Frith M, Grant CE, Clementi L, Ren J, Li WW, Noble WS, Suite MEME. Tools for motif discovery and searching Nucleic Acids Res. 2009. https://doi.org/10.1093/nar/gkp335.

67. Brennan L, Disatham J, Kantorow M. Hypoxia regulates the degradation of non-nuclear organelles during lens differentiation through activation of HIF1a. Exp Eye Res. 2020;198: 108129. https://doi.org/10.1016/j.exer. 2020.108129.

68. Ebong S, Yu C-R, Carper DA, Chepelinsky AB, Egwuagu CE. Activation of STAT signaling pathways and induction of suppressors of cytokine signaling (SOCS) proteins in mammalian lens by growth factors. Invest Ophthalmol Vis Sci. 2004;45:872-8.
69. Ebong S, Chepelinsky AB, Robinson ML, Zhao H, Yu CR, Egwuagu CE. Characterization of the roles of STAT1 and STAT3 signal transduction pathways in mammalian lens development. Mol Vis. 2004;10:122-31.

70. Cavalheiro GR, Matos-Rodrigues GE, Zhao Y, Gomes AL, Anand D, Predes D, de Lima S, Abreu JG, Zheng D, Lachke SA, Crekl A, Martins RAP. N-myc regulates growth and fiber cell differentiation in lens development. Dev Biol. 2017;429:105-17. https://doi.org/10.1016/J. YDBIO.2017.07.002.

71. Lee HY, Wroblewski E, Philips GT, Stair CN, Conley K, Reedy M, Mastick GS, Brown NL. Multiple requirements for Hes1 during early eye formation. Dev Biol. 2005;284:464-78. https://doi.org/10.1016/j.ydbio. 2005.06.010.

72. Ohtaka-Maruyama C, Wang X, Ge H, Chepelinsky AB. Overlapping Sp1 and AP2 binding sites in a promoter element of the lens-specific MIP gene. Nucleic Acids Res. 1998;26:407-14. https://doi.org/10. 1093/nar/26.2.407.

73. Gong L, Ji WK, Hu XH, Hu WF, Tang XC, Huang ZX, Li L, Liu M, Xiang SH, Wu E, Woodward Z, Liu YZ, Nguyen QD, Li DWC. Sumoylation differentially regulates Sp1 to control cell differentiation. Proc Natl Acad Sci USA. 2014;111:5574-9. https://doi.org/10.1073/pnas.1315034111.

74. Liu X, Zhou P, Fan F, Li D, Wu J, Lu Y, Luo Y. CpG site methylation in CRYAA promoter affect transcription factor Sp1 binding in human lens epithelial cells. BMC Ophthalmol. 2016. https://doi.org/10.1186/ s12886-016-0309-y.

75. Antosova B, Smolikova J, Borkovcova R, Strnad H, Lachova J, Machon $\mathrm{O}$, Kozmik Z. Ectopic activation of Wnt/ $\beta$-catenin signaling in lens fiber cells results in cataract formation and aberrant fiber cell differentiation. PLoS ONE. 2013. https://doi.org/10.1371/journal.pone. 0078279.

76. Reza HM, Urano A, Shimada N, Yasuda K. Sequential and combinatorial roles of maf family genes define proper lens development. Mol Vis. 2007;13:18.

77. Cvekl A, Yang Y, Chauhan BK, Cveklova K. Regulation of gene expression by Pax6 in ocular cells: a case of tissue-preferred expression of crystallins in lens. Int J Dev Biol. 2004;48:829-44. https://doi.org/10. 1387/ijdb.041866ac.

78. Suzuki-Kerr H, Baba Y, Tsuhako A, Koso H, Dekker JD, Tucker HO, Kuribayashi H, Watanabe S. Forkhead Box Protein P1 is dispensable for retina but essential for lens development. Investig Opthalmol Vis Sci. 2017;58:1916. https://doi.org/10.1167/iovs.16-20085.

79. Yoshida T, Yasuda K. Characterization of the chicken L-Maf, MafB and c-Maf in crystallin gene regulation and lens differentiation. Genes Cells. 2002;7:693-706.

80. Takeuchi T, Kudo T, Ogata K, Hamada M, Nakamura M, Kito K, Abe Y, Ueda N, Yamamoto M, Engel JD, Takahashi S. Neither MafA/L-Maf nor MafB is essential for lens development in mice. Genes Cells. 2009;14:941-7.

81. Agrawal SA, Anand D, Siddam AD, Kakrana A, Dash S, Scheiblin DA, Dang CA, Terrell AM, Waters SM, Singh A, Motohashi H, Yamamoto M, Lachke SA. Compound mouse mutants of bZIP transcription factors Mafg and Mafk reveal a regulatory network of non-crystallin genes associated with cataract. Hum Genet. 2015;134:717-35.

82. Cvekl A, McGreal R, Liu W. Lens development and crystallin gene expression. Prog Mol Biol Transl Sci. 2015;134:129-67. https://doi.org/ 10.1016/BS.PMBTS.2015.05.001.

83. Hoshino $\mathrm{H}$, Igarashi K. Expression of the oxidative stress-regulated transcription factor Bach2 in differentiating neuronal cells. J Biochem. 2002;132:427-31. https://doi.org/10.1093/oxfordjournals.jbchem. a003239.

84. Cvekl A, Kashanchi F, Brady JN, Piatigorsky J. Pax-6 interactions with TATA-box-binding protein and retinoblastoma protein. Investig Ophthalmol Vis Sci. 1999:40:1343-50.

85. Kim GN, Hah YS, Seong H, Yoo WS, Choi MY, Cho HY, Yun SP, Kim SJ. The role of nuclear factor of activated t cells 5 in hyperosmotic stressexposed human lens epithelial cells. Int J Mol Sci. 2021. https://doi. org/10.3390/ijms22126296.

86. Cavalheiro GR, Matos-Rodrigues GE, Gomes AL, Rodrigues PMG, Martins RAP. c-myc regulates cell proliferation during lens development. PLOS ONE. 2014. https://doi.org/10.1371/journal.pone.0087182. 
87. Le TT, Conley KW, Mead TJ, Rowan S, Yutzey KE, Brown NL. Requirements for Jag 1-Rbpj mediated Notch signaling during early mouse lens development. Dev Dyn. 2012;241:493-504.

88. Sun J, Rockowitz S, Chauss D, Wang P, Kantorow M, Zheng D, Cvekl A. Chromatin features, RNA polymerase II and the comparative expression of lens genes encoding crystallins, transcription factors, and autophagy mediators. Mol Vis. 2015;21:955-73.

89. Potts JD, Kornacker S, Beebe DC. Activation of the Jak-STAT-signaling pathway in embryonic lens cells. Dev Biol. 1998;204:277-92. https://doi. org/10.1006/dbio.1998.9077.

90. Cvekl A, McGreal R, Liu W. Lens development and crystallin gene expression. Prog Mol Biol Transl Sci. 2015. https://doi.org/10.1016/bs. pmbts.2015.05.001.

91. Gillespie MA, Palii CG, Sanchez-Taltavull D, Shannon P, Longabaugh WJR, Downes DJ, Sivaraman K, Espinoza HM, Hughes JR, Price ND, Perkins TJ, Ranish JA, Brand M. Absolute quantification of transcription factors reveals principles of gene regulation in erythropoiesis. Mol Cell. 2020;78:960-974.e11. https://doi.org/10.1016/J.MOLCEL.2020.03.031.

92. Brennan L, Disatham J, Kantorow M. Hypoxia regulates the degradation of non-nuclear organelles during lens differentiation through activation of HIF1a. Exp Eye Res. 2020. https://doi.org/10.1016/J.EXER.2020. 108129.

93. Chauss D, Basu S, Rajakaruna S, Ma Z, Gau V, Anastas S, Brennan LA, Hejtmancik JF, Menko AS, Kantorow M. Differentiation statespecific mitochondrial dynamic regulatory networks are revealed by global transcriptional analysis of the developing chicken lens. G3. 2014:4:1515-27. https://doi.org/10.1534/g3.114.012120.

94. Suzuki-Kerr H, Baba Y, Tsuhako A, Koso H, Dekker JD, Tucker HO, Kuribayashi $\mathrm{H}$, Watanabe S. Forkhead box protein P1 is dispensable for retina but essential for lens development. Investig Ophthalmol Vis Sci. 2017:58:1916-29. https://doi.org/10.1167/IOVS.16-20085.

95. Cui X, Wang L, Zhang J, Du R, Liao S, Li D, Li C, Ke T, Li DWC, Huang H, Yin Z, Tang Z, Liu M. HSF4 regulates DLAD expression and promotes lens de-nucleation. Biochim Biophys Acta. 1832;2013:1167-72. https:// doi.org/10.1016/J.BBADIS.2013.03.007.

96. Zhao G, Bailey CG, Feng Y, Rasko J, Lovicu FJ. Negative regulation of lens fiber cell differentiation by RTK antagonists Spry and Spred. Exp Eye Res. 2018;170:148-59. https://doi.org/10.1016/J.EXER.2018.02.025.

97. Underbjerg L, Sikjaer T, Mosekilde L, Rejnmark L. Pseudohypoparathyroidism - epidemiology, mortality and risk of complications. Clin Endocrinol. 2016;84:904-11. https://doi.org/10.1111/CEN.12948.

98. Burnett JB, Lupu Fl, Eggenschwiler JT. Proper ciliary assembly is critical for restricting Hedgehog signaling during early eye development in mice. Dev Biol. 2017:430:32-40. https://doi.org/10.1016/J.YDBIO.2017. 07.012.

99. Karnam S, Skiba NP, Rao PV. Biochemical and biomechanical characteristics of dystrophin-deficient mdx3cv mouse lens. Biochim Biophys Acta Mol Basis Dis. 2021. https://doi.org/10.1016/J.BBADIS.2020.165998.

100. Zhou Y, Bennett TM, Shiels A. Lens ER-stress response during cataract development in Mip-mutant mice. Biochim Biophys Acta Mol Basis Dis. 1862;2016:1433-42. https://doi.org/10.1016/J.BBADIS.2016.05.003.

101. Li H, Yang L, Sun Z, Yuan Z, Wu S, Sui R. A novel small deletion in the NHS gene associated with Nance-Horan syndrome. Sci Rep. 2018. https://doi.org/10.1038/S41598-018-20787-2.

102. Wenzel PL, Chong JL, Sáenz-Robles MT, Ferrey A, Hagan JP, Gomez YM, Rajmohan R, Sharma N, Chen HZ, Pipas JM, Robinson ML, Leone G. Cell proliferation in the absence of E2F1-3. Dev Biol. 2011;351:35-45. https:// doi.org/10.1016/J.YDBIO.2010.12.025.

103. Smigiel R, Cabala M, Jakubiak A, Kodera H, Sasiadek MJ, Matsumoto $N$, Sasiadek MM, Saitsu H. Novel COL4A1 mutation in an infant with severe dysmorphic syndrome with schizencephaly, periventricular calcifications, and cataract resembling congenital infection. Birth Defects Res A Clin Mol Teratol. 2016;106:304-7. https://doi.org/10.1002/BDRA.23488.

104. Kannan R, Stolz A, Ji O, Prasad PD, Ganapathy V. Vitamin C transport in human lens epithelial cells: evidence for the presence of SVCT2. Exp Eye Res. 2001:73:159-65. https://doi.org/10.1006/EXER.2001.1024.

105. Kanada F, Takamura Y, Miyake S, Kamata K, Inami M, Inatani M, Oki M. Histone acetyltransferase and Polo-like kinase 3 inhibitors prevent rat galactose-induced cataract. Sci Rep. 2019. https://doi.org/10.1038/ S41598-019-56414-X.
106. Garcia CM, Yu K, Zhao H, Ashery-Padan R, Ornitz DM, Robinson ML, Beebe DC. Signaling through FGF receptor-2 Is required for lens cell survival and for withdrawal from the cell cycle during lens fiber cell differentiation. Dev Dyn. 2005;233:516-27. https://doi.org/10.1002/DVDY. 20356.

107. Zhang Y, Fan J, Ho JWK, Hu T, Kneeland SC, Fan X, Xi Q, Sellarole MA, de Vries WN, Lu W, Lachke SA, Lang RA, John SWM, Maas RL. Crim1 regulates integrin signaling in murine lens development. Dev. 2016:143:356-66. https://doi.org/10.1242/DEV.125591.

108. Zhou Y, Shiels A. Epha2 and Efna5 participate in lens cell pattern-formation. Differentiation. 2018;102:1-9. https://doi.org/10.1016/J.DIFF.2018. 05.002 .

109. Shui YB, Wang X, Hu JS, Wang SP, Garcia CM, Potts JD, Sharma Y, Beebe DC. Vascular endothelial growth factor expression and signaling in the lens. Investig Ophthalmol Vis Sci. 2003:44:3911-9. https://doi.org/10. 1167/IOVS.02-1226.

110. Lu B, Christensen IT, Yu T, Wang C, Yan Q, Wang X. SUMOylation evoked by oxidative stress reduced lens epithelial cell antioxidant functions by increasing the stability and transcription of TP53INP1 in age-related cataracts. Oxid Med Cell Longev. 2019. https://doi.org/10.1155/2019/ 7898069 .

111. Ang SJ, Stump RJW, Lovicu FJ, McAvoy JW. Spatial and temporal expression of Wnt and Dickkopf genes during murine lens development. Gene Expr Patterns. 2004;4:289-95. https://doi.org/10.1016/J.MODGEP. 2003.11.002

112. Anand D, Lachke SA. Systems biology of lens development: a paradigm for disease gene discovery in the eye. Exp Eye Res. 2017;156:22-33. https://doi.org/10.1016/J.EXER.2016.03.010.

113. Islam F, Htun S, Lai LW, Krall M, Poranki M, Martin PM, Sobreira N, Wohler ES, Yu J, Moore AT, Slavotinek AM. Exome sequencing in patients with microphthalmia, anophthalmia, and coloboma (MAC) from a consanguineous population. Clin Genet. 2020;98:499-506. https://doi.org/10. 1111/CGE.13830

114. Palsamy P, Bidasee KR, Shinohara T. Selenite cataracts: activation of endoplasmic reticulum stress and loss of Nrf2/Keap1-dependent stress protection. Biochim Biophys Acta Mol Basis Dis. 1842;2014:1794-805. https://doi.org/10.1016/J.BBADIS.2014.06.028.

115. Jing R, Ma B, Qi T, Hu C, Liao C, Wen C, Shao Y, Pei C. Long noncoding RNA OIP5-AS1 inhibits cell apoptosis and cataract formation by blocking POLG expression under oxidative stress. Investig Ophthalmol Vis Sci. 2020. https://doi.org/10.1167/IOVS.61.12.3.

116. Wederell ED, de longh RU. Extracellular matrix and integrin signaling in lens development and cataract. Semin Cell Dev Biol. 2006;17:759-76. https://doi.org/10.1016/J.SEMCDB.2006.10.006.

117. Simirskii VN, Wang Y, Duncan MK. Conditional deletion of $\beta 1$-integrin from the developing lens leads to loss of the lens epithelial phenotype. Dev Biol. 2007;306:658-68. https://doi.org/10.1016/J.YDBIO.2007.04.004

118. Taiyab A, Holms J, West-Mays JA. $\beta$-Catenin/Smad3 interaction regulates transforming growth factor- $\beta$-induced epithelial to mesenchymal transition in the lens. Int J Mol Sci. 2019. https://doi.org/10.3390/IJMS2 0092078.

119. Swarup A, Bell BA, Du J, Han JYS, Soto J, Abel ED, Bravo-Nuevo A, FitzGerald PG, Peachey NS, Philp NJ. Deletion of GLUT1 in mouse lens epithelium leads to cataract formation. Exp Eye Res. 2018;172:45-53. https://doi.org/10.1016/J.EXER.2018.03.021.

120. Senthilkumari S, Talwar B, Dharmalingam K, Ravindran RD, Jayanthi R, Sundaresan P, Saravanan C, Young IS, Dangour AD, Fletcher AE. Polymorphisms in sodium-dependent vitamin $C$ transporter genes and plasma, aqueous humor and lens nucleus ascorbate concentrations in an ascorbate depleted setting. Exp Eye Res. 2014;124:24-30. https://doi. org/10.1016/J.EXER.2014.04.022

121. McGannon P, Miyazaki Y, Gupta PC, Traboulsi El, Colmenares C. Ocular abnormalities in mice lacking the Ski proto-oncogene. Investig Ophthalmol Vis Sci. 2006:47:4231-7. https://doi.org/10.1167/IOVS.05-1543.

122. Guo H, Tong P, Peng Y, Wang T, Liu Y, Chen J, Li Y, Tian Q, Hu Y, Zheng Y, Xiao L, Xiong W, Pan Q, Hu Z, Xia K. Homozygous loss-of-function mutation of the LEPREL1 gene causes severe non-syndromic high myopia with early-onset cataract. Clin Genet. 2014;86:575-9. https://doi.org/10. 1111/CGE.12309.

123. Sun M, Chen C, Hou S, Li X, Wang H, Zhou J, Chen X, Liu P, Kijlstra A, $\mathrm{Lin} S$, Ye J. A novel mutation of PANK4 causes autosomal dominant 
congenital posterior cataract. Hum Mutat. 2019;40:380-91. https://doi. org/10.1002/HUMU.23696.

124. Qin Y, Zhu Y, Luo F, Chen C, Chen X, Wu M. Killing two birds with one stone: dual blockade of integrin and FGF signaling through targeting syndecan-4 in postoperative capsular opacification. Cell Death Dis. 2017;8: e2920. https://doi.org/10.1038/CDDIS.2017.315.

125. Choi JJY, Ting CT, Trogrlic L, Milevski SV, Familari M, Martinez G, De longh RU. A role for smoothened during murine lens and cornea development. PLoS ONE. 2014. https://doi.org/10.1371/JOURNAL.PONE. 0108037.

126. Plageman TF, Chung MI, Lou M, Smith AN, Hildebrand JD, Wallingford JB, Lang RA. Pax6-dependent Shroom3 expression regulates apical constriction during lens placode invagination. Development. 2010;137:405-15. https://doi.org/10.1242/DEV.045369.

127. Manthey AL, Lachke SA, FitzGerald PG, Mason RW, Scheiblin DA, McDonald JH, Duncan MK. Loss of Sip1 leads to migration defects and retention of ectodermal markers during lens development. Mech Dev. 2014;131:86-110. https://doi.org/10.1016/J.MOD.2013.09.005.

128. Pirity MK, Wang WL, Wolf LV, Tamm ER, Schreiber-Agus N, Cvekl A. Rybp, a polycomb complex-associated protein, is required for mouse eye development. BMC Dev Biol. 2007. https://doi.org/10.1186/ 1471-213X-7-39.

129. Baba Y, Watabe Y, Sagara H, Watanabe S. Sall 1 plays pivotal roles for lens fiber cell differentiation in mouse. Biochem Biophys Res Commun. 2019;512:927-33. https://doi.org/10.1016/J.BBRC.2019.03.098.

130. Donner AL, Episkopou V, Maas RL. Sox2 and Pou2f1 interact to control lens and olfactory placode development. Dev Biol. 2007;303:784-99. https://doi.org/10.1016/J.YDBIO.2006.10.047.

131. Yoon KH, Fitzgerald PG. Periplakin interactions with lens intermediate and beaded filaments. Investig Ophthalmol Vis Sci. 2009;50:1283-9. https://doi.org/10.1167/IOVs.08-2894.

132. Wolf LV, Yang Y, Wang J, Xie Q, Braunger B, Tamm ER, Zavadil J, Cvekl A. Identification of Pax6-dependent gene regulatory networks in the mouse lens. PLoS ONE. 2009. https://doi.org/10.1371/JOURNAL.PONE. 0004159.

133. Moré MI, Kirsch FP, Rathjen FG. Targeted ablation of NrCAM or ankyrin-B results in disorganized lens fibers leading to cataract formation. J Cell Biol. 2001;154:187-96. https://doi.org/10.1083/JCB.200104038.

134. Shao M, LuT, Zhang C, Zhang YZ, Kong SH, Shi DL. Rbm24 controls poly(A) tail length and translation efficiency of crystallin mRNAs in the lens via cytoplasmic polyadenylation. Proc Natl Acad Sci USA. 2020;117:7245-54. https://doi.org/10.1073/PNAS.1917922117.

135. Dahm R, Procter JE, Ireland ME, Lo WK, Mogensen MM, Quinlan RA, Prescott AR. Reorganization of centrosomal marker proteins coincides with epithelial cell differentiation in the vertebrate lens. Exp Eye Res. 2007:85:696-713. https://doi.org/10.1016/J.EXER.2007.07.022.

136. Kellner U, Stöhr H, Weinitz S, Farmand G, Weber BHF. Mevalonate kinase deficiency associated with ataxia and retinitis pigmentosa in two brothers with MVK gene mutations. Ophthalmic Genet. 2017:38:340-4. https://doi.org/10.1080/13816810.2016.1227459.

137. Antosova B, Smolikova J, Klimova L, Lachova J, Bendova M, Kozmikova I, Machon O, Kozmik Z. The gene regulatory network of lens induction is wired through Meis-dependent shadow enhancers of Pax6. PLoS Genet. 2016. https://doi.org/10.1371/JOURNAL.PGEN.1006441.

138. Kantorow M, Hawse JR, Cowell TL, Benhamed S, Pizarro GO, Reddy VN, Hejtmancik JF. Methione sulfoxide reductase A is important for lens cell viability and resistance to oxidative stress. Proc Natl Acad Sci USA. 2004;101:9654-9. https://doi.org/10.1073/PNAS.0403532101.

139. Saravanamuthu SS, Gao CY, Zelenka PS. Notch signaling is required for lateral induction of Jagged 1 during FGF-induced lens fiber differentiation. Dev Biol. 2009;332:166-76. https://doi.org/10.1016/J.YDBIO.2009. 05.566.

140. Matteson PG, Desai J, Korstanje R, Lazar G, Borsuk TE, Rollins J, Kadambi S, Joseph J, Rahman T, Wink J, Benayed R, Paigen B, Millonig JH. The orphan G protein-coupled receptor, Gpr161, encodes the vacuolated lens locus and controls neurulation and lens development. Proc Natl Acad Sci USA. 2008;105:2088-93. https://doi.org/10.1073/PNAS.07056 57105.

141. Rumping L, Tessadori F, Pouwels PJW, Vringer E, Wijnen JP, Bhogal AA, Savelberg SMC, Duran KJ, Bakkers MJG, Ramos RJJ, Schellekens PAW, Kroes HY, Klomp DWJ, Black GCM, Taylor RL, Bakkers JPW, Prinsen HCMT,
Van Der Knaap MS, Dansen TB, Rehmann H, Zwartkruis FJT, Houwen RHJ, Van Haaften G, Verhoeven-Duif NM, Jans JJM, Van Hasselt PM. GLS hyperactivity causes glutamate excess, infantile cataract and profound developmental delay. Hum Mol Genet. 2019;28:96-104. https://doi.org/ 10.1093/HMG/DDY330.

142. Marchetti MA, Pizarro GO, Sagher D, DeAmicis C, Brot N, Hejtmancik JF, Weissbach $\mathrm{H}$, Kantorow M. Methionine sulfoxide reductases B1, $\mathrm{B} 2$, and $\mathrm{B} 3$ are present in the human lens and confer oxidative stress resistance to lens cells. Investig Ophthalmol Vis Sci. 2005;46:2107-12. https://doi.org/10.1167/IOVS.05-0018.

143. Barnum CE, Al Saai S, Patel SD, Cheng C, Anand D, Xu X, Dash S, Siddam AD, Glazewski L, Paglione E, Polson SW, Chuma S, Mason RW, Wei S, Batish M, Fowler VM, Lachke SA. The Tudor-domain protein TDRD7, mutated in congenital cataract, controls the heat shock protein HSPB1 (HSP27) and lens fiber cell morphology. Hum Mol Genet. 2021;29:2076-97. https://doi.org/10.1093/HMG/DDAA096.

144. Morales J, Al-Sharif L, Khalil DS, Shinwari JMA, Bavi P, Al-Mahrouqi RA, Al-Rajhi A, Alkuraya FS, Meyer BF, Al Tassan N. Homozygous mutations in ADAMTS10 and ADAMTS17 cause lenticular myopia, ectopia lentis, glaucoma, spherophakia, and short stature. Am J Hum Genet. 2009:85:558-68. https://doi.org/10.1016/J.AJHG.2009.09.011.

145. Wiggs JL, Pawlyk B, Connolly E, Adamian M, Miller JW, Pasquale LR, Haddadin RI, Grosskreutz CL, Rhee DJ, Li T. Disruption of the blood-aqueous barrier and lens abnormalities in mice lacking Lysyl Oxidase-Like 1 (LOXL1). Investig Ophthalmol Vis Sci. 2014;55:856-64. https://doi.org/10.1167/IOVS.13-13033.

146. Inoue T, Kagawa T, Inoue-Mochita M, Isono K, Ohtsu N, Nobuhisa I, Fukushima M, Tanihara H, Taga T. Involvement of the Hipk family in regulation of eyeball size, lens formation and retinal morphogenesis. FEBS Lett. 2010;584:3233-8. https://doi.org/10.1016/J.FEBSLET.2010. 06.020 .

147. Gao N, Li J, Qin Y, Wang Y, Kang Q, Pei C. SNAl1 interacts with HDAC1 to control TGF- $\beta 2$-induced epithelial-mesenchymal transition in human lens epithelial cells. Int J Mol Med. 2020;45:265-73. https:// doi.org/10.3892/IJMM.2019.4405.

148. Meyer LM, Löfgren S, Ho YS, Lou M, Wegener A, Holz F, Söderberg P. Absence of glutaredoxin 1 increases lens susceptibility to oxidative stress induced by UVR-B. Exp Eye Res. 2009;89:833-9. https://doi.org/ 10.1016/J.EXER.2009.07.020.

149. Zhao H, Yang T, Madakashira BP, Thiels CA, Bechtle CA, Garcia CM, Zhang H, Yu K, Ornitz DM, Beebe DC, Robinson ML. Fibroblast growth factor receptor signaling is essential for lens fiber cell differentiation. Dev Biol. 2008;318:276-88. https://doi.org/10.1016/J.YDBIO.2008.03. 028.

150. Wolf N, Penn P, Pendergrass W, Van Remmen H, Bartke A, Rabinovitch $P$, Martin GM. Age-related cataract progression in five mouse models for anti-oxidant protection or hormonal influence. Exp Eye Res. 2005;81:276-85. https://doi.org/10.1016/J.EXER.2005.01.024.

151. Chaffee BR, Hoang TV, Leonard MR, Bruney DG, Wagner BD, Dowd JR, Leone G, Ostrowski MC, Robinson ML. FGFR and PTEN signaling interact during lens development to regulate cell survival. Dev Biol. 2016;410:150-63. https://doi.org/10.1016/J.YDBIO.2015.12.027.

152. Rothe M, Kanwal N, Dietmann P, Seigfried FA, Hempel A, Schütz D, Reim D, Engels R, Linnemann A, Schmeisser MJ, Bockmann J, Kühl M, Boeckers TM, Kühl SJ. An Epha4/Sipa1/3/Wnt pathway regulates eye development and lens maturation. Dev. 2017;144:321-33. https://doi org/10.1242/DEV.147462.

153. Purcell P, Oliver G, Mardon G, Donner AL, Maas RL. Pax6-dependence of Six3, Eya1 and Dach1 expression during lens and nasal placode induction. Gene Expr Patterns. 2005;6:110-8. https://doi.org/10. 1016/J.MODGEP.2005.04.010.

154. Wormstone IM, Tamiya S, Eldred JA, Lazaridis K, Chantry A, Reddan JR, Anderson I, Duncan G. Characterisation of TGF- $\beta 2$ signalling and function in a human lens cell line. Exp Eye Res. 2004;78:705-14. https://doi.org/10.1016/J.EXER.2003.08.006.

155. Anand D, Al Saai S, Shrestha SK, Barnum CE, Chuma S, Lachke SA. Genome-wide analysis of differentially expressed miRNAs and their associated regulatory networks in lenses deficient for the congenital cataract-linked tudor domain containing protein TDRD7. Front Cell Dev Biol. 2021. https://doi.org/10.3389/FCELL.2021.615761. 
156. Omi N, Kiyokawa E, Matsuda M, Kinoshita K, Yamada S, Yamada K, Matsushima Y, Wang Y, Kawai J, Suzuki M, Hayashizaki Y, Hiai H. Mutation of Dock5, a member of the guanine exchange factor Dock180 superfamily, in the rupture of lens cataract mouse. Exp Eye Res. 2008;86:828-34. https://doi.org/10.1016/J.EXER.2008.02.011.

157. Lin Q, Zhou N, Zhang N, Qi Y. Mutational screening of EFNA5 in Chinese age-related cataract patients. Ophthalmic Res. 2014;52:124-9. https:// doi.org/10.1159/000363139

158. Zhao W, Zhao W, Zhao J, Wang D, Li J. Screening of potential target genes for cataract by analyzing mRNA expression profile of mouse Hsf4-null lens. BMC Ophthalmol. 2015. https://doi.org/10.1186/ S12886-015-0066-3.

159. Tam OH, Pennisi D, Wilkinson L, Little MH, Wazin F, Wan VL, Lovicu FJ. Crim1 is required for maintenance of the ocular lens epithelium. Exp Eye Res. 2018;170:58-66. https://doi.org/10.1016/J.EXER.2018.02.012.

160. Fan J, Lerner J, Wyatt MK, Cai P, Peterson K, Dong L, Wistow G. The klotho-related protein KLPH (Ictl) has preferred expression in lens and is essential for expression of clic5 and normal lens suture formation. Exp Eye Res. 2018;169:111-21. https://doi.org/10.1016/J.EXER.2018.02.001.

161. Pfirrmann T, Emmerich D, Ruokonen P, Quandt D, Buchen R, FischerZirnsak B, Hecht J, Krawitz P, Meyer P, Klopocki E, Stricker S, Lausch E, Seliger B, Hollemann T, Reinhard T, Auw-Haedrich C, Zabel B, Hoffmann K, Villavicencio-Lorini P. Molecular mechanism of CHRDL1-mediated $X$-linked megalocornea in humans and in Xenopus model. Hum Mol Genet. 2014;24:3119-32. https://doi.org/10.1093/HMG/DDV063.

162. Ha TT, Sadleir LG, Mandelstam SA, Paterson SJ, Scheffer IE, Gecz J, Corbett MA. A mutation in COL4A2 causes autosomal dominant porencephaly with cataracts. Am J Med Genet Part A. 2016;170:1059-63. https://doi.org/10.1002/AJMG.A.37527.

163. Van Esch H, Jansen A, Bauters M, Froyen G, Fryns JP. Encephalopathy and bilateral cataract in a boy with an interstitial deletion of Xp22 comprising the CDKL5 and NHS genes. Am J Med Genet Part A. 2007;143:364-9. https://doi.org/10.1002/AJMG.A.31572.

164. Clendenon SG, Sarmah S, Shah B, Liu Q, Marrs JA. Zebrafish cadherin-11 participates in retinal differentiation and retinotectal axon projection during visual system development. Dev Dyn. 2012;241:442-54. https:// doi.org/10.1002/DVDY.23729.

165. Martinez G, Wijesinghe M, Turner K, Abud HE, Taketo MM, Noda T, Robinson ML, de longh RU. Conditional mutations of $\beta$-Catenin and APC reveal roles for canonical Wnt signaling in lens differentiation. Investig Ophthalmol Vis Sci. 2009;50:4794-806. https://doi.org/10.1167/IOVS. 09-3567.

166. Zhao Y, Wilmarth PA, Cheng C, Limi S, Fowler VM, Zheng D, David LL, Cvekl A. Proteome-transcriptome analysis and proteome remodeling in mouse lens epithelium and fibers. Exp Eye Res. 2019;179:32-46. https:// doi.org/10.1016/J.EXER.2018.10.011.

167. Lin HJ, Huang YC, Lin JM, Liao WL, Wu JY, Chen CH, Chou YC, Chen LA, Lin CJ, Tsai FJ. Novel susceptibility genes associated with diabetic cataract in a Taiwanese population. Ophthalmic Genet. 2013;34:35-42. https://doi.org/10.3109/13816810.2012.736590.

168. Zha C, Farah CA, Holt RJ, Ceroni F, Al-Abdi L, Thuriot F, Khan AO, Helaby R, Lévesque S, Alkuraya FS, Kraus A, Ragge NK, Sossin WS. Biallelic variants in the small optic lobe calpain CAPN15 are associated with congenital eye anomalies, deafness and other neurodevelopmental deficits. Hum Mol Genet. 2020;29:3054-63. https://doi.org/10.1093/ HMG/DDAA198.

169. Lin L, Lin Q, Li J, Han Y, Chang P, Lu F, Zhao YE. ROCK inhibitor modified intraocular lens as an approach for inhibiting the proliferation and migration of lens epithelial cells and posterior capsule opacification. Biomater Sci. 2019;7:4208-17. https://doi.org/10.1039/C9BM00787C.

170. Ragge N, Isidor B, Bitoun P, Odent S, Giurgea I, Cogné B, Deb W, Vincent M, Le Gall J, Morton J, Lim D, Le Meur G, Zazo Seco C, Zafeiropoulou D, Bax D, Zwijnenburg P, Arteche A, Swafiri ST, Cleaver R, McEntagart M, Kini U, Newman W, Ayuso C, Corton M, Herenger Y, Jeanne M, Calvas P, Chassaing N. Expanding the phenotype of the X-linked BCOR microphthalmia syndromes. Hum Genet. 2019;138:1051-69. https://doi.org/10. 1007/S00439-018-1896-X.

171. Chang C, Zhang K, Veluchamy A, Hébert HL, Looker HC, Colhoun HM, Palmer CNA, Meng W. A genome-wide association study provides new evidence that CACNA1C gene is associated with diabetic cataract.
Investig Ophthalmol Vis Sci. 2016;57:2246-50. https://doi.org/10.1167/ IOVS.16-19332.

172. Cantù C, Zimmerli D, Hausmann G, Valenta T, Moor A, Aguet M, Basler K. Pax6-dependent, but $\beta$-catenin-independent, function of $B c 19$ proteins in mouse lens development. Genes Dev. 2014;28:1879-84. https://doi. org/10.1101/GAD.246140.114.

173. de Maria A, Shi Y, Luo X, van der Weyden L, Bassnett S. Cadm1 expression and function in the mouse lens. Investig Ophthalmol Vis Sci. 2011:52:2293-9. https://doi.org/10.1167/IOVS.10-6677.

174. Choquet H, Melles RB, Anand D, Yin J, Cuellar-Partida G, Wang W, Hoffmann TJ, Nair KS, Hysi PG, Lachke SA, Jorgenson E. A large multiethnic GWAS meta-analysis of cataract identifies new risk loci and sex-specific effects. Nat Commun. 2021. https://doi.org/10.1038/ S41467-021-23873-8

175. Xiang J, Kang L, Gao H, Wu J, Qin B, Zhou T, Zhang G, Guan H. BLM can regulate cataract progression by influencing cell vitality and apoptosis. Exp Eye Res. 2019;178:99-107. https://doi.org/10.1016/J.EXER.2018.08. 022.

176. Sugiyama Y, Shelley EJ, Yoder BK, Kozmik Z, May-Simera HL, Beales PL, Lovicu FJ, McAvoy JW. Non-essential role for cilia in coordinating precise alignment of lens fibres. Mech Dev. 2016;139:10-7. https://doi.org/10. 1016/J.MOD.2016.01.003.

177. Song S, Landsbury A, Dahm R, Liu Y, Zhang Q, Quinlan RA. Functions of the intermediate filament cytoskeleton in the eye lens. J Clin Invest. 2009;1 19:1837-48. https://doi.org/10.1172/JCI38277.

178. Wride MA. Lens fibre cell differentiation and organelle loss: many paths lead to clarity. Philos Trans R Soc B Biol Sci. 2011;366:1219-33. https:// doi.org/10.1098/RSTB.2010.0324.

179. Chauhan BK, Disanza A, Choi SY, Faber SC, Lou M, Beggs HE, Scita G, Zheng Y, Lang RA. Cdc42- and IRSp53-dependent contractile filopodia tether presumptive lens and retina to coordinate epithelial invagination. Development. 2009;136:3657-67. https://doi.org/10.1242/DEV. 042242.

180. Cui X, Feng R, Wang J, Du C, Pi X, Chen D, Li J, Li H, Zhang J, Zhang J, Mu $H$, Zhang F, Liu M, Hu Y. Heat shock factor 4 regulates lysosome activity by modulating the aB-crystallin-ATP6V1A-mTOR complex in ocular lens. Biochim Biophys Acta Gen Subj. 2020. https://doi.org/10.1016/J. BBAGEN.2019.129496.

181. Wenke JL, McDonald WH, Schey KL. Spatially directed proteomics of the human lens outer cortex reveals an intermediate filament switch associated with the remodeling zone. Investig Ophthalmol Vis Sci. 2016:57:4108-14. https://doi.org/10.1167/IOVS.16-19791.

182. Valverde P, Obin MS, Taylor A. Role of Gas6/Axl signaling in lens epithelial cell proliferation and survival. Exp Eye Res. 2004;78:27-37. https:// doi.org/10.1016/J.EXER.2003.10.002.

183. Takenouchi T, Yoshihashi H, Sakaguchi Y, Uehara T, Honda M, Takahashi T, Kosaki K, Miyama S. Hirschsprung disease as a yet undescribed phenotype in a patient with ARID1B mutation. Am J Med Genet Part A. 2016;170:3249-52. https://doi.org/10.1002/AJMG.A.37861.

184. Firtina Z, Duncan MK. Unfolded protein response (UPR) is activated during normal lens development. Gene Expr Patterns. 2011;11:135-43. https://doi.org/10.1016/J.GEP.2010.10.005.

185. Chauss D, Basu S, Rajakaruna S, Ma Z, Gau V, Anastas S, Brennan LA, Hejtmancik JF, Menko AS, Kantorow M. Differentiation state-specific mitochondrial dynamic regulatory networks are revealed by global transcriptional analysis of the developing chicken lens. G3. 2014. https://doi.org/10.1534/g3.114.012120.

186. Parker DS, Wawrousek EF, Piatigorsky J. Expression of the delta-crystallin genes in the embryonic chicken lens. Dev Biol. 1988;126:375-81. https://doi.org/10.1016/0012-1606(88)90147-9.

187. Gao M, Huang Y, Wang L, Huang M, Liu F, Liao S, Yu S, Lu Z, Han S, Hu X, Qu Z, Liu X, Assefa Yimer T, Yang L, Tang Z, Li DW-C, Liu M. HSF4 regulates lens fiber cell differentiation by activating p53 and its downstream regulators. Cell Death Dis. 2017;8:e3082. https://doi.org/10.1038/cddis. 2017.478.

188. Shi X, Cui B, Wang Z, Weng L, Xu Z, Ma J, Xu G, Kong X, Hu L. Removal of Hsf4 leads to cataract development in mice through down-regulation of gamma S-crystallin and Bfsp expression. BMC Mol Biol. 2009. https:// doi.org/10.1186/1471-2199-10-10.

189. Jia J, Lin M, Zhang L, York JP, Zhang P. The Notch signaling pathway controls the size of the ocular lens by directly suppressing p57Kip2 
expression. Mol Cell Biol. 2007;27:7236-47. https://doi.org/10.1128/ MCB.00780-07.

190. Azimi M, Brown NL. Jagged1 protein processing in the developing mammalian lens. Biol Open. 2019. https://doi.org/10.1242/bio.041095.

191. Garcia CM, Shui YB, Kamath M, DeVillar J, Johnson RS, Gerber HP, Ferrara $\mathrm{N}$, Robinson ML, Beebe DC. The function of VEGF-A in lens development: formation of the hyaloid capillary network and protection against transient nuclear cataracts. Exp Eye Res. 2009;88:270-6. https:// doi.org/10.1016/j.exer.2008.07.017.

192. Kerr CL, Huang J, Williams T, West-Mays JA. Activation of the hedgehog signaling pathway in the developing lens stimulates ectopic FoxE3 expression and disruption in fiber cell differentiation. Invest Ophthalmol Vis Sci. 2012;53:3316-30. https://doi.org/10.1167/IOVS.12-9595.

193. Tsonis PA, Vergara MN, Spence JR, Madhavan M, Kramer EL, Call MK, Santiago WG, Vallance JE, Robbins DJ, Del Rio-Tsonis K. A novel role of the hedgehog pathway in lens regeneration. Dev Biol. 2004;267:45061. https://doi.org/10.1016/J.YDBIO.2003.12.005.

194. Lovicu FJ, Shin EH, MCAvoy JW. Fibrosis in the lens. Sprouty regulation of TGF $\beta$-signaling prevents lens EMT leading to cataract. Exp Eye Res. 2016;142:92-101. https://doi.org/10.1016/J.EXER.2015.02.004.

195. Shirai K, Tanaka S-I, Lovicu FJ, Saika S. The murine lens: a model to investigate in vivo epithelial-mesenchymal transition. Dev Dyn. 2018;247:340-5. https://doi.org/10.1002/DVDY.24518.

196. Hejtmancik JF, Riazuddin SA, McGreal R, Liu W, Cvekl A, Shiels A. Lens biology and biochemistry. Prog Mol Biol Transl Sci. 2015;134:169-201. https://doi.org/10.1016/BS.PMBTS.2015.04.007.

197. Andley UP, Patel HC, Xi J-H, Bai F. Identification of genes responsive to UV-A radiation in human lens epithelial cells using complementary DNA microarrays. Photochem Photobiol. 2004;80:61. https://doi.org/10. 1562/2004-02-03-RA-075.1.

198. Shaham O, Smith AN, Robinson ML, Taketo MM, Lang RA, Ashery-Padan R. Pax6 is essential for lens fiber cell differentiation. Development. 2009;136:2567-78. https://doi.org/10.1242/dev.032888.

199. Zhao Y, Zheng D, Cvekl A. A comprehensive spatial-temporal transcriptomic analysis of differentiating nascent mouse lens epithelial and fiber cells. Exp Eye Res. 2018;175:56-72. https://doi.org/10.1016/J.EXER.2018. 06.004 .

200. Walker JL, Zhang L, Menko AS. Transition between proliferation and differentiation for lens epithelial cells is regulated by Src family kinases. Dev Dyn. 2002;224:361-72. https://doi.org/10.1002/dvdy.10115.

201. Awasthi N, Wagner BJ. Interferon-gamma induces apoptosis of lens alphaTN4-1 cells and proteasome inhibition has an antiapoptotic effect. Invest Ophthalmol Vis Sci. 2004;45:222-9. https://doi.org/10.1167/IOVS. 03-0571.

202. Awasthi N, Wagner BJ. Upregulation of heat shock protein expression by proteasome inhibition: an antiapoptotic mechanism in the lens. Invest Ophthalmol Vis Sci. 2005;46:2082-91. https://doi.org/10.1167/ IOVS.05-0002.

203. Kondoh H, Uchikawa M, Kamachi Y. Interplay of Pax6 and SOX2 in lens development as a paradigm of genetic switch mechanisms for cell differentiation. Int J Dev Biol. 2004;48:819-27. https://doi.org/10.1387/ IJDB.041868HK.

204. Ra L. Pathways regulating lens induction in the mouse. Int J Dev Biol. 2004;48:783-91. https://doi.org/10.1387/JJDB.041903RL.

205. Hervouet E, Vallette FM, Cartron PF. Dnmt3/transcription factor interactions as crucial players in targeted DNA methylation. Epigenetics. 2009:4:487-99. https://doi.org/10.4161/EPI.4.7.9883.

206. Hoang TV, Horowitz ER, Chaffee BR, Qi P, Flake RE, Bruney DG, Rasor BJ, Rosalez SE, Wagner BD, Robinson ML. Lens development requires DNMT1 but takes place normally in the absence of both DNMT3A and DNMT3B activity. Epigenetics. 2017. https://doi.org/10.1080/15592294. 2016.1253651

207. Loo SK, Suzina SS, Musa M, Wong KK. DNMT1 is associated with cell cycle and DNA replication gene sets in diffuse large B-cell lymphoma. Pathol Res Pract. 2018;214:134-43. https://doi.org/10.1016/J.PRP.2017. 10.005 .

208. Ma HS, Wang EL, Xu WF, Yamada S, Yoshimoto K, Qian ZR, Shi L, Liu LL, Li $\mathrm{XH}$. Overexpression of DNA (Cytosine-5)-methyltransferase 1 (DNMT1) and DNA (Cytosine-5)-methyltransferase 3A (DNMT3A) is associated with aggressive behavior and hypermethylation of tumor suppressor genes in human pituitary adenomas. Med Sci Monit. 2018;24:4841-50. https://doi.org/10.12659/MSM.910608.

209. Wang P, Chu W, Zhang X, Li B, Wu J, Qi L, Yu Y, Zhang H. Kindlin-2 interacts with and stabilizes DNMT1 to promote breast cancer development. Int J Biochem Cell Biol. 2018;105:41-51. https://doi.org/10.1016/J. BIOCEL.2018.09.022

210. Jeong Y, Jun Y, Kim J, Park H, Choi K-S, Zhang H, Park JA, Kwon J-Y, Kim Y-M, Lee S, Kwon Y-G. Integrative analysis of DNA methylation and mRNA expression during differentiation of umbilical cord blood derived mononuclear cells to endothelial cells. Gene. 2017;635:48-60. https://doi.org/10.1016/J.GENE.2017.09.006.

211. Mo A, Mukamel EA, Davis FP, Luo C, Henry GL, Picard S, Urich MA, Nery JR, Sejnowski TJ, Lister R, Eddy SR, Ecker JR, Nathans J. Epigenomic signatures of neuronal diversity in the mammalian brain. Neuron. 2015;86:1369-84. https://doi.org/10.1016/J.NEURON.2015.05.018.

212. Rizzardi LF, Hickey PF, DiBlasi VR, Tryggvadóttir R, Callahan CM, Idrizi A, Hansen KD, Feinberg AP. Neuronal brain-region-specific DNA methylation and chromatin accessibility are associated with neuropsychiatric trait heritability. Nat Neurosci. 2019;22:307-16. https://doi.org/10.1038/ S41593-018-0297-8.

213. Farlik M, Halbritter F, Müller F, Choudry FA, Ebert P, Klughammer J, Farrow S, Santoro A, Ciaurro V, Mathur A, Uppal R, Stunnenberg HG, Ouwehand WH, Laurenti E, Lengauer T, Frontini M, Bock C. DNA methylation dynamics of human hematopoietic stem cell differentiation. Cell Stem Cell. 2016;19:808-22. https://doi.org/10.1016/J.STEM.2016.10.019.

214. Spainhour JCG, Lim HS, Yi SV, Qiu P. Correlation patterns between DNA methylation and gene expression in the Cancer Genome Atlas. Cancer Inform. 2019. https://doi.org/10.1177/1176935119828776.

215. Lim YC, Li J, Ni Y, Liang Q, Zhang J, Yeo GSH, Lyu J, Jin S, Ding C. A complex association between DNA methylation and gene expression in human placenta at first and third trimesters. PLOS ONE. 2017;12: e0181155. https://doi.org/10.1371/JOURNAL.PONE.0181155.

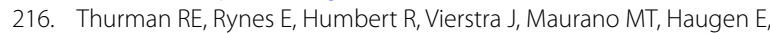
Sheffield NC, Stergachis AB, Wang H, Vernot B, Garg K, John S, Sandstrom R, Bates D, Boatman L, Canfield TK, Diegel M, Dunn D, Ebersol AK, Frum T, Giste E, Johnson AK, Johnson EM, Kutyavin T, Lajoie B, Lee B-K, Lee K, London D, Lotakis D, Neph S, Neri F, Nguyen ED, Qu H, Reynolds AP, Roach V, Safi A, Sanchez ME, Sanyal A, Shafer A, Simon JM, Song L, Vong S, Weaver M, Yan Y, Zhang Z, Zhang Z, Lenhard B, Tewari M, Dorschner MO, Hansen RS, Navas PA, Stamatoyannopoulos G, lyer VR, Lieb JD, Sunyaev SR, Akey JM, Sabo PJ, Kaul R, Furey TS, Dekker J, Crawford GE, Stamatoyannopoulos JA. The accessible chromatin landscape of the human genome. Nature. 2012;489:75-82. https://doi.org/10. 1038/NATURE11232.

217. Disatham J, Chauss D, Gheyas R, Brennan L, Blanco D, Daley L, Menko AS, Kantorow M. Lens differentiation is characterized by stage-specific changes in chromatin accessibility correlating with differentiation statespecific gene expression. Dev Biol. 2019;453:86-104. https://doi.org/10. 1016/j.ydbio.2019.04.020.

218. Zhong Z, Feng S, Duttke SH, Potok ME, Zhang Y, Gallego-Bartolomé J, Liu W, Jacobsen SE. DNA methylation-linked chromatin accessibility affects genomic architecture in Arabidopsis. Proc Natl Acad Sci USA. 2021;118:2022. https://doi.org/10.1073/PNAS.2023347118/-/DCSUP PLEMENTAL.

219. Robertson KD. DNA methylation and chromatin—unraveling the tangled web. Oncogene. 2002;21:5361-79. https://doi.org/10.1038/sj.onc. 1205609.

220. Corces MR, Trevino AE, Hamilton EG, Greenside PG, Sinnott-Armstrong NA, Vesuna S, Satpathy AT, Rubin AJ, Montine KS, Wu B, Kathiria A, Cho SW, Mumbach MR, Carter AC, Kasowski M, Orloff LA, Risca VI, Kundaje A, Khavari PA, Montine TJ, Greenleaf WJ, Chang HY. An improved ATAC-seq protocol reduces background and enables interrogation of frozen tissues. Nat Methods. 2017;14:959-62. https://doi.org/10.1038/nmeth. 4396.

221. Krueger F, Andrews SR. Bismark: a flexible aligner and methylation caller for Bisulfite-Seq applications. Bioinformatics. 2011;27:1571-2. https:// doi.org/10.1093/BIOINFORMATICS/BTR167.

222. Feng $\mathrm{H}$, Conneely KN, Wu H. A Bayesian hierarchical model to detect differentially methylated loci from single nucleotide resolution sequencing data. Nucleic Acids Res. 2014. https://doi.org/10.1093/NAR/ GKU154. 
223. Park Y, Wu H. Differential methylation analysis for BS-seq data under general experimental design. Bioinformatics. 2016;32:1446-53. https:// doi.org/10.1093/BIOINFORMATICS/BTW026.

224. Martin M. Cutadapt removes adapter sequences from high-throughput sequencing reads. EMBnet J. 2011;17:10. https://doi.org/10.14806/ej. 17.1.200.

225. Langmead B, Salzberg SL. Fast gapped-read alignment with Bowtie 2. Nat Methods. 2012;9:357-9. https://doi.org/10.1038/nmeth.1923.

226. Kim D, Langmead B, Salzberg SL. HISAT: a fast spliced aligner with low memory requirements. Nat Methods. 2015;12:357-60. https://doi.org/ 10.1038/nmeth.3317.

227. Pertea M, Pertea GM, Antonescu CM, Chang TC, Mendell JT, Salzberg SL. StringTie enables improved reconstruction of a transcriptome from RNA-seq reads. Nat Biotechnol. 2015;33:290-5. https://doi.org/10.1038/ nbt.3122.

228. Robinson MD, McCarthy DJ, Smyth GK. edgeR: a Bioconductor package for differential expression analysis of digital gene expression data. Bioinformatics. 2009;26:139-40. https://doi.org/10.1093/bioinformatics/ btp616.

229. Kent WJ, Sugnet CW, Furey TS, Roskin KM, Pringle TH, Zahler AM, Haussler AD. The human genome browser at UCSC. Genome Res. 2002;12:996-1006. https://doi.org/10.1101/gr.229102.

230. Liberzon A, Subramanian A, Pinchback R, Thorvaldsdóttir H, Tamayo P, Mesirov JP. Molecular signatures database (MSigDB) 3.0. Bioinformatics. 2011. https://doi.org/10.1093/bioinformatics/btr260.

231. Khan A, Fornes O, Stigliani A, Gheorghe M, Castro-Mondragon JA, van der Lee R, Bessy A, Chèneby J, Kulkarni SR, Tan G, Baranasic D, Arenillas DJ, Sandelin A, Vandepoele K, Lenhard B, Ballester B, Wasserman WW, Parcy F, Mathelier A. JASPAR 2018 update of the open-access database of transcription factor binding profiles and its web framework. Nucleic Acids Res. 2018;46(2018):D260-6. https://doi.org/10.1093/nar/gkx1126.

232. Grant CE, Bailey TL, Noble WS. FIMO: scanning for occurrences of a given motif. Bioinformatics. 2011;27:1017-8. https://doi.org/10.1093/ BIOINFORMATICS/BTR064.

\section{Publisher's Note}

Springer Nature remains neutral with regard to jurisdictional claims in published maps and institutional affiliations.

Ready to submit your research? Choose BMC and benefit from:

- fast, convenient online submission

- thorough peer review by experienced researchers in your field

- rapid publication on acceptance

- support for research data, including large and complex data types

- gold Open Access which fosters wider collaboration and increased citations

- maximum visibility for your research: over $100 \mathrm{M}$ website views per year

At BMC, research is always in progress.

Learn more biomedcentral.com/submissions 